\title{
Codes of Best Practice in Competitive Markets for Managers*
}

\author{
Eduard Alonso-Paulí ${ }^{\dagger} \quad$ David Pérez-Castrillo ${ }^{\ddagger}$
}

January 2010

\begin{abstract}
We study the corporate governance of firms in environments where possibly heterogeneous shareholders compete for possibly heterogeneous managers. A firm, formed by a shareholder and a manager, can sign either an incentive contract or a contract including a Code of Best Practice. A Code allows for better management control, but makes it hard for managers to react quickly when market conditions change. Codes tend to be adopted in markets with low volatility and in environments where managers obtain low levels of benefits. The firms with the best projects tend to adopt a Code when managers are not too heterogeneous, while the best managers tend to be hired through incentive contracts when the projects are similar. Although the matching between shareholders and managers is often positively assortative, shareholders with the best projects might be willing to renounce hiring the best managers; instead, signing contracts including Codes with lower-ability managers.
\end{abstract}

${ }^{*}$ We thank Inés Macho-Stadler, Pau Olivella, Nicolas Porteiro, Pedro Rey, Vicente López-Cuñat and an anonymous referee, as well as seminar participants at the Universities of Brown, Padova, Venezia, Autónoma de Barcelona and Queen's at Belfast, and participants in presentations at the Third Congress of the Game Theory Society (Chicago) and the Summer School on Corporate Governance (Santander) for their helpful comments. We gratefully acknowledge financial support from projects SEJ2009-07616-ECON, ECO2008-04321/ECON, 2009SGR-169, Consolider-Ingenio CSD200600016, Barcelona Economics-Xarxa CREA and ICREA Academia.

${ }^{\dagger}$ Dept. of Economics, Universidad Pablo Olavide. Email: ealonso@upo.es.

${ }^{\ddagger}$ Corresponding author: Dept. of Economics \& CODE, Universitat Autònoma de Barcelona, 08193 Bellaterra (Barcelona), Spain. Email: david.perez@uab.es. Tel: 349358114 05. Fax: 34935812461. 
JEL Classification numbers: G-34, D-82

Keywords: Corporate Governance, Incentives, Moral Hazard, Matching model, Sharpe Ratio.

\section{Introduction}

The last two decades have witnessed the creation and diffusion of Codes of Best Practice (or Codes of Corporate Governance) all around the world. A Code of Best Practice is a list of rules promoted by a regulator suggesting how a firm should supervise management. A Code's recommendations cover a wide range of corporate governance issues: for example, board structure, executive compensation, and the role played by institutional investors and capital structure (Becht et al., 2002). Yet, the two most relevant features shared by any Code of Best Practice are, first, its voluntary nature ${ }^{1}$ and, second, its purpose to improve management oversight. ${ }^{2}$

In this paper, we analyze the implementation of Codes in markets where possibly heterogeneous shareholders compete for possibly heterogeneous managers. ${ }^{3}$ We study which firms use Codes and how this depends on the characteristics of the set of shareholders and managers, as well as each firm's output market. We model each firm as an agency relationship (Jensen and Meckling, 1976), where each shareholder hires one manager to conduct her project. A shareholder can hire a manager either through an incentive contract or through a contract that includes a Code of Best Practice. The success of each project depends on the decisions taken by the manager and also on product market conditions. Both the shareholder and manager know the (ex-ante) distribution of the market conditions parameter; however, only the manager learns the actual realization of the market conditions once the contract has been signed.

The adoption of the Code is a mechanism that allows the shareholder to reduce the

\footnotetext{
${ }^{1}$ In some countries, the legislation requires firms either to comply with each rule or to explain why they do not comply ("comply or explain" principle).

${ }^{2}$ The introduction of Codes of Best Practice was instigated by the Cadbury Report (1992). See, for instance, Aguilera et al. (2004) for the number and diffusion of Codes of Best Practice. See also IOSCO (2006) for a recent survey of compliance with Board Independence rules proposed by OECD (2004), which can be considered the standard for Codes of Best Practice.

${ }^{3}$ We analyze contracts for top executive managers. We have in mind managers whose decisions strongly influence the firms' profits. In most cases, only CEOs (Chief Executive officers) have such a power.
} 
manager's discretion (see, for instance, Dahya et al., 2002). However, this improvement in the board's control may be accompanied by a decrease in flexibility at the level of manager's decisions, thus affecting the firm's competitiveness, as argued by Sir Owen Green, former BTR Chairman:

"There is danger in an over-emphasis on monitoring; on non-executive directors' independence from the business of the corporation; on controls over decision making activities of companies. When coupled with the clearly reduced status of executives on the governing boards, such requirements must blunt the competitive edge and deflect the entrepreneurial drive which characterises participation, let alone success, in a free market." (Sir Owen Green, Pall Mall Lecture on UK Corporate Governance, February 25,1994)

We model this trade-off in a simple way: a manager's payment depends on the final outcome if he is hired through an incentive contract while a Code allows the shareholder to propose a contract specifying (ex-ante) the manager's decisions. Thus, a shareholder chooses between a contract that easily adjusts to the environment, but requires her to provide incentives to the manager and a (Code) contract that allows her to reduce the manager's rents but imposes large costs if market conditions are extreme since no adjustment is possible.

In the study of one isolated partnership, we show that a Code is more likely to be adopted when projects are highly profitable, managers are efficient, have low exogenous outside opportunities and there is a low variance in market conditions.

The main purpose of our paper is the analysis of the adoption of Codes in environments where shareholders compete for managers, so that the identities of the matched partners and their levels of utility, in addition to the contract, are endogenous rather than exogenous. For this purpose, we follow the approach adopted in papers such as Dam and Pérez-Castrillo (2006), Legros and Newmann (2007) and Serfes (2008). We model a twosided market where the transaction involves a contract. We take stability as the solution concept for this market. An outcome (i.e., a matching between shareholders and managers and a set of contracts) is stable if it can not be blocked by a shareholder-manager pair who would sign a more profitable contract for both parties. ${ }^{4}$

\footnotetext{
${ }^{4}$ Stability and competitive equilibrium are very close concepts. For matching models where the parties
} 
The analysis of the shareholder-manager competitive market gives rise to several interesting results. First, in environments where shareholders own projects with different expected returns while all managers have the same ability to conduct them, Codes are adopted by those shareholders with the best projects. Second, when the market is composed of homogeneous shareholders and heterogeneous managers, the best managers are hired through incentive contracts in such a way that the Code of Best Practice is only implemented in the relationships involving lower-ability managers (contrary to the conclusion obtained in the analysis of an isolated relationship).

Third, when both sides consist of heterogeneous agents, we determine conditions under which the matching is positively assortative: that is, shareholders with better projects hire better managers. This is always the case when either all the contracts in a stable outcome are based on incentives, or they all include Codes. Fourth, we identify situations where the matching is not positively assortative due to the coexistence of both types of contract. A shareholder with a good project may opt for a contract including a Code of Best Practice, attracting a less efficient manager when the more efficient one is "too expensive" because he is being hired in the market through an incentive contract. Finally, we discuss the welfare effects of introducing Codes of Best Practice. Albeit its voluntary nature, the use of Codes is not always welfare enhancing. We find that, in general, introducing Codes tends to be welfare enhancing if the environment displays a low variance, while it decreases welfare in environments with intermediate variance.

The literature dealing with Codes of Best Practice is still very scarce. With regard to the theoretical literature, Alonso-Paulí (2007) models a Code as a mechanism that prevents the manager from taking certain (bad) actions. He investigates the effect of its adoption on managers' incentives and studies the design of the optimal Code by a regulator. The empirical literature investigates the relation among corporate governance provisions, the introduction of a Code, and firms' performances. This analysis has not reached a consensus in its conclusions. For instance, while Arcot and Bruno (2006), Gompers et al. (2003) and Fernández and Gómez (2002) find positive effects of the adoption of the Code in the US, the UK and Spain, respectively, whereas Nowak et al. decide on money instead of contracts see, for instance, Shapley and Shubik (1972), Roth and Sotomayor (1990) and Pérez-Castrillo and Sotomayor (2002). Any stable outcome is also a competitive equilibrium and viceversa. 
(2004) and De Jong et al. (2006), find no effect of Codes' recommendations for Germany and the Netherlands.

Our paper is in line with a long tradition of studies on corporate governance mechanisms, such as takeovers, large shareholders, boards of directors and managers' compensations to solve the agency problem between shareholders and managers. Regarding the disciplinary role of the market, the influential papers by Grossman and Hart (1980) and Scharfstein (1988) study the main effects of the threat of takeovers and establish the takeover guidelines for this mechanism to be effective. On the role played by large shareholders, Admati et al. (1994) show that large shareholders tend to under-monitor because they balance the benefits of monitoring the manager against the costs of having undiversified portfolios. On the contrary, over-monitoring may arise, for instance, if shareholders enjoy private benefits of control (La Porta et al., 1998). Hermalin and Weisbach (1998) and Adams and Ferreira (2007) have developed important contributions to understanding the functioning of the board of directors. Hermalin and Weisbach (1998) analyze the process by which directors get selected and the influence of the manager on this process. Adams and Ferreira (2007) study the monitoring and the advising tasks developed by any board of directors. Finally, the role played by an appropriately chosen executive compensation scheme has been extensively studied (see, for instance, the pioneering work by Jensen and Meckling, 1976).

In analyzing markets where agents from two sides match, Dam and Pérez-Castrillo (2006) characterize a market with homogeneous principals and heterogeneous agents enjoying limited liability, whereas Serfes (2008) studies a market with heterogeneous principals and agents with CARA utility functions. Legros and Newmann (2007) provide sufficient conditions for monotone matchings in environments where, as is the case in our framework, utility is not fully transferable. Their "generalized increasing differences" property requires that the shareholder's willingness to pay to attract a better manager should increase with the value of her project, a property that does not hold when shareholders have the possibility of introducing a Code. Finally, Besley and Ghatak (2005) emphasize the virtues of mission-orientation and matching in a framework where the agents care about the firm they are matched with.

The paper is organized as follows. In Section 2, we present the main features of the model and the corresponding solution concept. The properties of the contract in 
stable outcomes are stated in Section 3. Section 4 studies particular manager-shareholder markets and provides characteristics for the most general environment. The welfare effect of introducing Codes is discussed in Section 5. Finally, Section 6 concludes the paper and discuses some extensions of the model. All proofs are included in the Appendix.

\section{The Model}

\subsection{Shareholders and Managers}

We consider the market for managers where $n$ risk-neutral shareholders $\mathcal{S}=\left\{s_{1}, s_{2}, s_{3}, \ldots, s_{n}\right\}$ meet $N$ risk neutral managers $\mathcal{M}=\left\{m_{1}, m_{2}, m_{3}, \ldots, m_{N}\right\}$. We denote shareholders by $s$, $s_{i}, s_{i^{\prime}}$, etc. and, similarly, managers are represented by $m, m_{j}, m_{j^{\prime}}$, etc. Each shareholder owns a project but lacks the skills to develop it. Each manager has the ability to conduct one project. Thus, shareholders and managers have to match up in pairs to carry out projects and a contract is signed for each partnership. Managers enjoy limited liability over income: their wage can not be negative under any conditions.

Both shareholders and managers may be heterogeneous agents. Shareholders may differ in the profitability of the projects they own while managers may diverge in their ability to conduct shareholders' projects. We allow for the possibility that both shareholders and managers can seek alternative partners and sign new contracts. Hence, the matching between shareholders and managers will be endogenous.

\subsection{Projects}

Once a shareholder-manager pair is formed, a firm is constituted and the manager is in charge of making decisions concerning the project. We assume for simplicity that projects are independent in the sense that, once constituted, a firm's profits only depend on decisions made in that firm. The project yields revenue $R_{i}>0$ for shareholder $s_{i}$ if it is successful, whereas the asset has value 0 in case of failure. The values of $R_{i}$, for $i=1, \ldots n$, are public information. Without loss of generality, we order the projects as $R_{1} \geq R_{2} \geq \ldots \geq R_{n}>0$. The probability of success of the project depends on the

manager's decision or effort $e$ and on the realization $h$ of some random shock $\widetilde{h}$. In particular, we assume that the probability of success is $e h$. 
The effort of manager $m_{j}$ is his own private information, and it has a cost $c_{j}(e)=c_{j} \frac{e^{2}}{2}$, with $c_{j}>0$. The managers' abilities (the inverses of $c_{j}$ ) are public information, and we order the managers depending on their ability: $0<c_{1} \leq c_{2} \leq \ldots \leq c_{N}$; that is, a lower index corresponds to a more efficient manager.

The random variable $\widetilde{h}$ represents the uncertainty in the output market of a project. This industry-specific component can reflect differences among sectors, countries, etc. It is common knowledge that the realization $h$ is distributed according to $F(h)$ on the interval $[\underline{h}, \bar{h}]$ and it is revealed only to the manager after he accepts the contract and before he decides on the effort. We denote by $\alpha=\int_{\underline{h}}^{\bar{h}} h d F(h)$ the mean and by $\operatorname{Var}=$ $\int_{\underline{h}}^{\bar{h}} h^{2} d F(h)-\left[\int_{\underline{h}}^{\bar{h}} h d F(h)\right]^{2}$ the variance of the random shock.

Given the objective functions of the participants in a firm, the First-Best level of effort corresponds to the optimal effort for the joint shareholder/manager firm with the objective function $\pi_{s_{i}, m_{j}}^{F B}(e, h)=h e R_{i}-\frac{c_{j} e^{2}}{2}$. Therefore, the optimal First-Best effort is contingent on the realization of the random shock $\widetilde{h}$ :

$$
e_{i j}^{F B}(h)=\frac{R_{i} h}{c_{j}} .
$$

Finally, since we assume that the probability of the project's success is given by $e h$, an additional assumption is required to ensure that the condition $e h \leq 1$ always holds. One sufficient condition is

$$
\frac{R_{1}}{c_{1}} \bar{h}^{2} \leq 1
$$

Indeed, under this assumption $e h \leq 1$ for the First-Best level of effort decided by the best possible partnership in the most favorable realization of $\widetilde{h}$. Hence, $e h \leq 1$ will also hold for the level of effort associated to any contract signed in this market, since it will never be higher than the First-Best level

We denote by $\{\mathcal{S}, \mathcal{M}, \mathbf{R}, \mathbf{c}\}$ the market for managers and shareholders, where $\mathbf{R} \equiv$ $\left(R_{1}, R_{2}, \ldots, R_{n}\right)$ denotes the vector of the shareholders' projects and $\mathbf{c} \equiv\left(c_{1}, c_{2}, \ldots, c_{n}\right)$ corresponds to the vector of the managers' abilities.

\subsection{Contracts and payoffs}

When shareholder $s_{i}$ and manager $m_{j}$ form a firm, they sign a contract that will govern their relationship. The contract can be based on an incentive scheme (IS contract) or it 
can include a Code of Best Practices (CBP contract).

An IS contract for the firm $\left(s_{i}, m_{j}\right)$ takes the form $W_{s_{i}, m_{j}}^{I S}=\left(w_{i, j}^{R}, w_{i, j}^{0}\right)$. The first component $w_{i, j}^{R}$ is the transfer to the manager in case revenue $R_{i}$ is obtained; the second part $w_{i, j}^{0}$ is the transfer in case of failure, when the result is 0 . Under contract $\left(w_{i, j}^{R}, w_{i, j}^{0}\right)$, the manager will select the effort $e_{i, j}\left(w_{i, j}^{R}, w_{i, j}^{0} ; h\right)$ once he has observed the realization $h$ :

$$
e_{i, j}\left(w_{i, j}^{R}, w_{i, j}^{0} ; h\right)=\arg \max _{e}\left\{w_{i, j}^{0}+h e\left(w_{i, j}^{R}-w_{i, j}^{0}\right)-c_{j} \frac{e^{2}}{2}\right\},
$$

which implies that the level of effort is

$$
e_{i, j}\left(w_{i, j}^{R}, w_{i, j}^{0} ; h\right)=\frac{h}{c_{j}}\left(w_{i, j}^{R}-w_{i, j}^{0}\right) .
$$

The previous equation represents the Incentive Compatibility Constraint $(I C C)$. It states that the manager exerts a higher level of effort if the bonus is large $\left(w_{i, j}^{R}-w_{i, j}^{0}\right)$, if the market conditions are particularly profitable (high $h$ ), or if he has good skills (low $c_{j}$ ).

Alternatively, the firm $\left(s_{i}, m_{j}\right)$ can sign a CBP contract. A CBP is a monitoring technology that allows the shareholder to gather better information about the manager's decisions. We model the adoption of a Code in a very simple way: the board's control allows them to make the manager's decisions ex-ante contractual, i.e., the shareholder can ask the manager for any specific level of effort. Although the manager's decisions are ex-ante contractible, the shareholders still do not know the realization of the market conditions. Therefore, the agency problem between the manager and the shareholder is not fully solved. A CBP contract for firm $\left(s_{i}, m_{j}\right)$ is then a vector $W_{s_{i}, m_{j}}^{C B P}=\left(w_{i, j}^{R}, w_{i, j}^{0}, e_{i, j}\right)$ that specifies the payments to the manager as well as the effort he must exert.

Any contract must be acceptable to both the manager and the shareholder. Both agents must be better off signing the contract than staying apart from the market. Contract $W_{s_{i}, m_{j}}$ is acceptable to shareholder $s_{i}$ if it offers her non-negative profits. It is acceptable to manager $m_{j}$ if his expected utility under $W_{s_{i}, m_{j}}$ is not lower than the utility he would obtain by exiting the market. We call this the "outside utility" and denote it $\underline{U}$. We write the previous Acceptability constraints as follows:

$$
\begin{aligned}
& \pi_{s_{i}}\left(m_{j}, W_{s_{i}, m_{j}}\right) \geq 0, \\
& V_{m_{j}}\left(s_{i}, W_{s_{i}, m_{j}}\right) \geq \underline{U},
\end{aligned}
$$

where $\pi_{s_{i}}\left(m_{j}, W_{s_{i}, m_{j}}\right)$ is shareholder $s_{i}$ 's expected profits and $V_{m_{j}}\left(s_{i}, W_{s_{i}, m_{j}}\right)$ is manager $m_{j}$ 's expected utility when they sign the contract $W_{s_{i}, m_{j}}$. 
Furthermore, contracts have to satisfy managers' limited liability constraints:

$$
\begin{aligned}
& w_{i, j}^{R} \geq 0, \\
& w_{i, j}^{0} \geq 0 .
\end{aligned}
$$

Contracts that are not acceptable to one of the parties or that do not satisfy limited liability constraints will be discarded. We say that they are not feasible contracts.

Definition $1 \mathrm{~A}$ contract $W_{s_{i}, m_{j}}$ is feasible for $\left(s_{i}, m_{j}\right)$ if it satisfies the acceptability and limited liability constraints (ACs), $(A C m),\left(L L_{R}\right)$, and $\left(L L_{0}\right)$.

\subsection{Matching}

We represent the identity of the partners forming firms through a matching function that associates shareholders with managers. We now describe a matching in this economy.

Definition $2 A$ (one-to-one) matching for the market $\{\mathcal{S}, \mathcal{M}, \mathbf{R}, \mathbf{c}\}$ is a mapping $\mu$ : $\mathcal{S} \cup \mathcal{M} \longrightarrow \mathcal{S} \cup \mathcal{M}$ such that (i) $\mu\left(s_{i}\right) \in \mathcal{M} \cup\left\{s_{i}\right\}$ for all $s_{i} \in \mathcal{S}$, (ii) $\mu\left(m_{j}\right) \in \mathcal{S} \cup\left\{m_{j}\right\}$ for all $m_{j} \in \mathcal{M}$, and (iii) $\mu\left(s_{i}\right)=m_{j}$ if and only if $\mu\left(m_{j}\right)=s_{i}$ for all $\left(s_{i}, m_{j}\right) \in \mathcal{S} \times \mathcal{M}$.

The firm $\left(s_{i}, m_{j}\right)$ is formed under the matching $\mu$ if $\mu\left(s_{i}\right)=m_{j}$ (or, analogously, $\left.\mu\left(m_{j}\right)=s_{i}\right)$. The matching function also indicates when an agent (shareholder or manager) is not involved in any firm: $\mu\left(s_{i}\right)=s_{i}$ or $\mu\left(m_{j}\right)=m_{j}$.

In addition, we need to describe which contract governs any relationship. The only constraint is that contracts within a firm must be feasible.

Definition $3 A$ menu of contracts $\mathcal{W}$ that is compatible with a matching $\mu$ for the market $\{\mathcal{S}, \mathcal{M}, \mathbf{R}, \mathbf{c}\}$ is a vector of feasible contracts, one for each firm formed under $\mu$.

A matching and a set of contracts determine an organization of the market that we will refer to as an outcome.

Definition 4 An outcome $(\mu, \mathcal{W})$ for the market $\{\mathcal{S}, \mathcal{M}, \mathbf{R}, \mathbf{c}\}$ is a matching $\mu$ and a menu of contracts $\mathcal{W}$ compatible with $\mu$. 
The objective of our paper is to characterize the equilibrium outcomes in the shareholders/managers market. To be an equilibrium, the outcome $(\mu, \mathcal{W})$ must be immune to potential blocking from any shareholder-manager pair. This idea corresponds to the concept of stability and states that it is not sensible to expect $(\mu, \mathcal{W})$ to be a (stable or equilibrium) outcome of the market if there exists any shareholder-manager pair that can form a firm by signing a feasible contract such that both the shareholder and the manager are better-off under the new deal compared to the initial situation $(\mu, \mathcal{W})$.

Definition 5 An outcome $(\mu, \mathcal{W})$ for the market $\{\mathcal{S}, \mathcal{M}, \mathbf{R}, \mathbf{c}\}$ is stable if there does not exist any pair $\left(s_{i}, m_{j}\right)$ and any contract $W^{\prime}$ feasible for $\left(s_{i}, m_{j}\right)$ such that $\pi_{s_{i}}\left(m_{j}, W^{\prime}\right)>$ $\pi_{s_{i}}\left(\mu\left(s_{i}\right), W_{s_{i}, \mu\left(s_{i}\right)}\right)$ and $V_{m_{j}}\left(s_{i}, W^{\prime}\right)>V_{m_{j}}\left(\mu\left(m_{j}\right), W_{\mu\left(m_{j}\right), m_{j}}\right)$.

Since contracts in a stable outcome are feasible, they are also individually rational.

\section{Contracts in a stable outcome}

In this section, we take a first look at the characteristics of contracts signed in stable outcomes of market $\{\mathcal{S}, \mathcal{M}, \mathbf{R}, \mathbf{c}\}$. The first characteristic is that it is not possible for the partners of any existing firm to sign an alternative contract that both find better than the current contract. That is, contracts in a stable outcome are Pareto optimal among those feasible contracts that satisfy (in the case of incentive contracts) incentive constraints. We refer to this notion as (constrained) Pareto Optimality:

Definition 6 A contract $W_{s_{i}, m_{j}}$ for a firm $\left(s_{i}, m_{j}\right)$ is constrained Pareto optimal if there is no other feasible contract $W^{\prime}$ for $\left(s_{i}, m_{j}\right)$ such that $\pi_{s_{i}}\left(m_{j}, W^{\prime}\right) \geq \pi_{s_{i}}\left(m_{j}, W_{s_{i}, m_{j}}\right)$ and $V_{m_{j}}\left(s_{i}, W^{\prime}\right) \geq V_{m_{j}}\left(s_{i}, W_{s_{i}, m_{j}}\right)$, with at least one strict inequality.

Proposition 1 states the optimality property.

Proposition 1 All the contracts in a stable outcome for the market $\{\mathcal{S}, \mathcal{M}, \mathbf{R}, \mathbf{c}\}$ are constrained Pareto optimal.

The property of constrained Pareto optimality allows us to identify any contract in a stable outcome once we know the identity of the partners $\left(s_{i}, m_{j}\right)$ and the utility obtained 
by manager $m_{j}$. Indeed, the contract is the one that maximizes shareholder $s_{i}$ 's expected profits under the constraint that manager $m_{j}$ gets this utility level.

In the rest of the section, we characterize the best contract from the point of view of shareholder $s_{i}$ 's as a function of any possible "reservation utility" level $\underline{U}_{j}$ that has to be achieved by the manager. We denote such a contract as $W_{s_{i}, m_{j}}\left(\underline{U}_{j}\right) .^{5}$ Note that the level $\underline{U}_{j}$ will be an equilibrium reservation utility level, influenced by the possibility that manager $m_{j}$ forms a partnership with other shareholders. We first identify the contract if $\left(s_{i}, m_{j}\right)$ sign an Incentive Scheme contract $W_{s_{i}, m_{j}}^{I S}\left(\underline{U}_{j}\right)$ then, we calculate the best contract including a $\mathrm{CBP} W_{s_{i}, m_{j}}^{C B P}\left(\underline{U}_{j}\right)$. Finally, as a function of the reservation utility $\underline{U}_{j}$, we state which type of contract is chosen.

The impact of limited liability on $I S$ contracts and on payoffs is a function of the level of manager's utility level $\underline{U}_{j}$. For low values of $\underline{U}_{j}$, the optimal payment scheme depends only on the value of the project $R_{i}$. The shareholder shares half of the value in case of success and the manager ends up with a utility larger than $\underline{U}_{j}$. For large values of $\underline{U}_{j}$, the optimal payment scheme is also affected by $\underline{U}_{j}$ as this is the utility level that must be provided to the manager. The threshold, denoted by $\widehat{U}_{i j}$, that divides both regions depends on the value of the project and on the distribution of the market specific component as well as on the efficiency of the manager. Formally,

$$
\widehat{U}_{i j}=\frac{R_{i}^{2}}{c_{j}} \frac{\left[\operatorname{Var}+\alpha^{2}\right]}{8} .
$$

Finally, note that shareholder $s_{i}$ will not find a contract with manager $m_{j}$ acceptable if she obtains negative profits. This situation arises for $\underline{U}_{j}>\widetilde{U}_{i j} \equiv \frac{R_{i}^{2}}{c_{j}} \frac{\left[\operatorname{Var}+\alpha^{2}\right]}{2}$. We summarize these findings and identify the contract $W_{s_{i}, m_{j}}^{I S}\left(\underline{U}_{j}\right)$ in Proposition 2 .

Proposition 2 If $\left(s_{i}, m_{j}\right)$ sign an IS contract $W_{s_{i}, m_{j}}^{I S}\left(\underline{U}_{j}\right)$ in a stable outcome for the market $\{\mathcal{S}, \mathcal{M}, \mathbf{R}, \mathbf{c}\}$, then:

(a) $\underline{U}_{j} \leq \widetilde{U}_{i j}$ and the manager's expected utility is $U_{j}=\max \left\{\widehat{U}_{i j}, \underline{U}_{j}\right\}$;

(b) the transfers under $W_{s_{i}, m_{j}}^{I S}\left(\underline{U}_{j}\right)$ are $w_{i, j}^{0}=0$ and $w_{i, j}^{R}=\sqrt{\frac{2 c_{j} U_{j}}{\left[\operatorname{Var}+\alpha^{2}\right]}}$;

\footnotetext{
${ }^{5}$ As we will see, the optimal IS contract when shareholder $s_{i}$ has to ensure manager $m_{j}$ at least $\underline{U}_{j}$ may provide him a level of utility higher than $\underline{U}_{j}$ (due to the limited liability constraint). That is, $\underline{U}_{j}$ might not be the manager's actual utility. However, we compute the optimal shareholder's contract for any possible $\underline{U}_{j}$ as it is the most direct way to proceed in our analysis.
} 
(c) the manager's effort as a function of $h$ is $e_{i, j}^{I S}(h)=h \sqrt{\frac{2 U_{j}}{c_{j}\left[V a r+\alpha^{2}\right]}}$;

(d) the shareholder's expected profits are $\pi_{s_{i}}\left(W_{s_{i}, m_{j}}^{I S}\left(\underline{U}_{j}\right)\right)=R_{i} \sqrt{\frac{2\left[\operatorname{Var}+\alpha^{2}\right] U_{j}}{c_{j}}}-2 U_{j}$.

Figure 1 depicts shareholder $s_{i}$ 's profits as a function of manager $m_{j}$ 's reservation utility $\underline{U}_{j}$. For any $\underline{U}_{j}$ in the interval $\left[0, \widehat{U}_{i j}\right)$, the optimal contract is the same. It provides the manager an expected utility level of $\widehat{U}_{i j}$, which is larger than the minimum utility $\underline{U}_{j}$. Since the manager is protected by limited liability, his salary in case of failure can not be lower than zero. Providing incentives for effort requires paying a bonus to the manager in case of success. The optimal bonus from the shareholder's perspective ensures the manager a utility level of $\widehat{U}_{i j}$, which is higher than $\underline{U}_{j}$ when the latter is low. When $\underline{U}_{j} \in\left[\widehat{U}_{i j}, \widetilde{U}_{i j}\right]$, the efficiency of the (contingent) manager's effort increases with $\underline{U}_{j}$; it goes from $e_{i j}^{I S}(h)=e_{i j}^{F B}(h) / 2$ when $\underline{U}_{j}=\widehat{U}_{i j}$ to $e_{i j}^{I S}(h)=e_{i j}^{F B}(h)$ when $\underline{U}_{j}=\widetilde{U}_{i j}$. Indeed, the shareholder provides the required higher utility by increasing the salary in case of success (and keeping $w_{i, j}^{0}=0$ ). Intuitively, the profits increase with the value of the project $R_{i}$ and with the manager's efficiency (the inverse of $c_{j}$ ).

Finally, market conditions, as measured by the variance and the mean of the distribution of $\widetilde{h}$, have a crucial impact on shareholder's profits under an IS contract. As expected, a larger mean implies larger shareholder's profits; a larger variance, maybe more surprisingly, also leads to larger profits. To give an intuition on the latter effect, note that both shareholder and manager are risk-neutral agents and this would suggest that variance has no effect on profits. This would happen if effort would be independent of the realization of the market conditions. However, the manager adjusts $e$ to the realization $h$. Given the complementarity between effort and market conditions (since the probability of the project's success is given by $e h$ ), an increase in $h$ leads the manager to also increase $e$. Therefore, the profit function is a convex function of $h$ and, under the optimal contract, profits are increasing with the variance. 


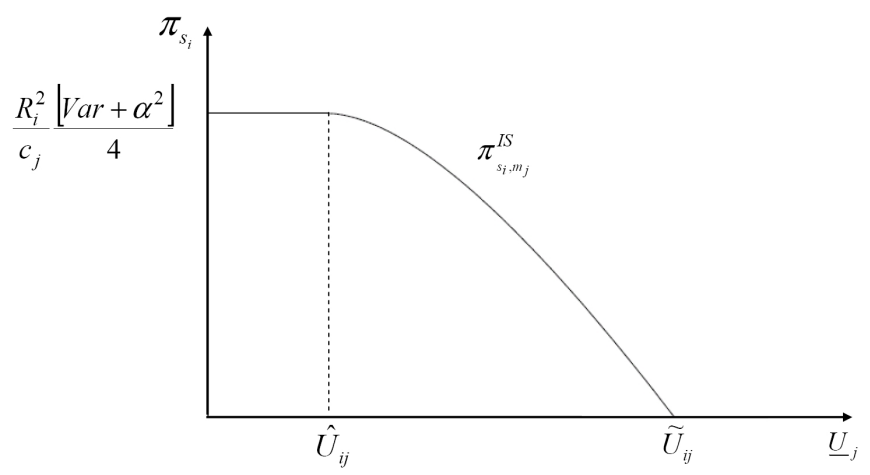

Figure 1: Shareholder's profits under Incentive contracts

Since the effort is contractible under a CBP contract and both participants are riskneutral, the only role played by the payment scheme in $W_{s_{i}, m_{j}}^{C B P}\left(\underline{U}_{j}\right)$ is to compensate the manager. Therefore, a fixed payment is always optimal. ${ }^{6}$ Proposition 3 summarizes the characteristics of the contract when the Code is adopted:

Proposition 3 If $\left(s_{i}, m_{j}\right)$ sign a $C B P$ contract in a stable outcome for the market $\{\mathcal{S}, \mathcal{M}, \mathbf{R}, \mathbf{c}\}$, then the following $W_{s_{i}, m_{j}}^{C B P}\left(\underline{U}_{j}\right)$ is an optimal contract: ${ }^{7}$

(a) the manager's effort under $W_{s_{i}, m_{j}}^{C B P}\left(\underline{U}_{j}\right)$ is $e_{i, j}^{C B P}=\frac{R_{i}}{c_{j}} \alpha$;

(b) the transfers are $w_{i, j}^{R}=w_{i, j}^{0}=\underline{U}_{j}+\frac{R_{i}^{2}}{c_{j}} \frac{\alpha^{2}}{2}$;

(c) $\underline{U}_{j} \leq \frac{R_{i}^{2}}{c_{j}} \frac{\alpha^{2}}{2}$ and the manager obtains a utility of $\underline{U}_{j}$;

(d) the shareholder's expected profits are $\pi_{s_{i}}\left(W_{s_{i}, m_{j}}^{C B P}\left(\underline{U}_{j}\right)\right)=\frac{R_{i}^{2}}{c_{j}} \frac{\alpha^{2}}{2}-\underline{U}_{j}$.

\footnotetext{
${ }^{6}$ In some firms, the monitoring technology may be more powerful than the one suggested by our model, allowing the shareholder not only to verify whether the contractual effort (or decision) is provided but also to check whether the manager provides an effort level at least as high as the contractual effort (or a decision at least as beneficial as the contractual decision). Then, a variable payment scheme together with the contractual effort would be better than a fixed payment: it would induce the manager to provide a higher effort in case of excellent market conditions. We exclude this possibility for simplicity and to highlight the loss of flexibility incurred by adopting the Code.

${ }^{7}$ The risk-neutrality of shareholders and managers implies that any pair $\left\{w_{i, j}^{R}, w_{i, j}^{0}\right\} \geq(0,0)$, such that

$$
w_{i, j}^{0}+\alpha e_{i, j}^{C B P}\left(w_{i, j}^{R}-w_{i, j}^{0}\right)-\frac{1}{2} c_{j}\left(e_{i, j}^{C B P}\right)^{2}=\underline{U}_{j},
$$
}

where $e_{i, j}^{C B P}=\frac{R_{i}}{c_{j}} \alpha$, is also an optimal contract. 
The optimal ex-ante level of effort that maximizes the shareholder's profits depends on the value of the project $R_{i}$, the manager's efficiency (the inverse of $c_{j}$ ) and also on $\alpha$, the average value of the market conditions. Since the manager's effort must be selected ex-ante and the shareholder does not know the true market conditions, the optimal level of effort is taken as if the true realization were in fact the mean of the distribution; this is the choice that minimizes the potential losses from an ex-post deviation from $e_{i j}^{F B}(h)$.

Once we have studied the characteristics of $W_{s_{i}, m_{j}}^{I S}\left(\underline{U}_{j}\right)$ and $W_{s_{i}, m_{j}}^{C B P}\left(\underline{U}_{j}\right)$, we proceed to analyze whether shareholder $s_{i}$ prefers to propose an IS contract or a CBP contract as a function of $\underline{U}_{j}$ and the distribution of the market conditions. To this end, we capture the market conditions by the Sharpe ratio. It states how good the ex-ante market conditions are after the market volatility is taken into account. This ratio, also known as the rewardto-variability index, has been extensively used to study the excess of return per unit of risk in an investment strategy or a trading strategy. ${ }^{8}$ In what follows, we define the Sharpe ratio of the distribution $F(h)$ as

$$
S r=\frac{\alpha}{\sqrt{\operatorname{Var}}} .
$$

Proposition 4 characterizes the optimal contract. ${ }^{9}$

Proposition 4 Shareholder $s_{i}$ obtains higher profits with the contract $W_{s_{i}, m_{j}}^{C B P}\left(\underline{U}_{j}\right)$ than with $W_{s_{i}, m_{j}}^{I S}\left(\underline{U}_{j}\right)$ if and only if $S r>1$ and $\underline{U}_{j}<U_{i j}^{*}$, where

$$
\begin{aligned}
U_{i j}^{*} & \equiv \frac{R_{i}^{2}}{c_{j}} \frac{\left[\sqrt{\left[V a r+\alpha^{2}\right]}-\sqrt{V a r}\right]^{2}}{2} \text { if } S r \geq \sqrt{3} ; \text { and } \\
U_{i j}^{*} & \equiv \frac{R_{i}^{2}}{2 c_{j}}\left[\frac{\alpha^{2}-V a r}{2}\right] \text { if } S r \in(1, \sqrt{3}) .
\end{aligned}
$$

Proposition 4 states the conditions for the optimal contract to include a Code of Best Practice. Adopting a CBP requires, given a fixed mean of the market conditions, sufficiently low variance in the environment $(S r>1)$ and a sufficiently low manager's utility level $\left(\underline{U}_{j}<U_{i j}^{*}\right){ }^{10}$ Under the CBP contract, the shareholder fully internalizes

\footnotetext{
${ }^{8}$ For a more detailed analysis of the Sharpe ratio, see Sharpe (1994).

${ }^{9} \mathrm{We}$ adopt the convention that the IS contract will be selected in case of indifference.

${ }^{10}$ In line with our results, Inderst et al. (2005) and Dow and Raposo (2005), among others, study the optimal IS contract and show that the intensity of the incentives should increase with the market volatility. Prendergast (2002) also points out that, contrary to the traditional analysis of the agency model and based on the inconclusive empirical work, incentive schemes are more prone to be adopted under volatile environments. Depending on the environment faced by the firms, managers's payments may be dependent on input (effort) rather than on output (i.e., revenues).
} 
the manager's costs by providing him the constant utility $\underline{U}_{j}$ and solving the problem $\max _{e}\left\{\alpha e R_{i}-c_{j} \frac{e^{2}}{2}-\underline{U}_{j}\right\}$. If the variance of $\widetilde{h}$ is low, the shareholder's problem, and hence, the manager's effort and the shareholder's profits with the CBP contract are similar to those of the joint firm, i.e., they are close to the First-Best. Under the IS contract, the shareholder decides the bonus $\left(w_{i, j}^{R}-w_{i, j}^{0}\right)$ and the effort is chosen by the manager as a solution to $\max _{e}\left\{w_{i, j}^{0}+h e\left(w_{i, j}^{R}-w_{i, j}^{0}\right)-c_{j} \frac{e^{2}}{2}\right\}$. If the manager's utility $\underline{U}_{j}$ is low, the shareholder only needs to provide a low bonus for the manager to accept the contract; hence the manager's choice of effort will be much lower than the First-Best choice. Therefore, the CBP contract dominates the IS one when both the variance of $\widetilde{h}$ and the manager's utility $\underline{U}_{j}$ are low. Otherwise, it is better to let the manager adjust the effort by properly choosing the payment scheme. Figure 2 illustrates the effect of the manager's utility on the adoption decision when the environment is not too volatile.

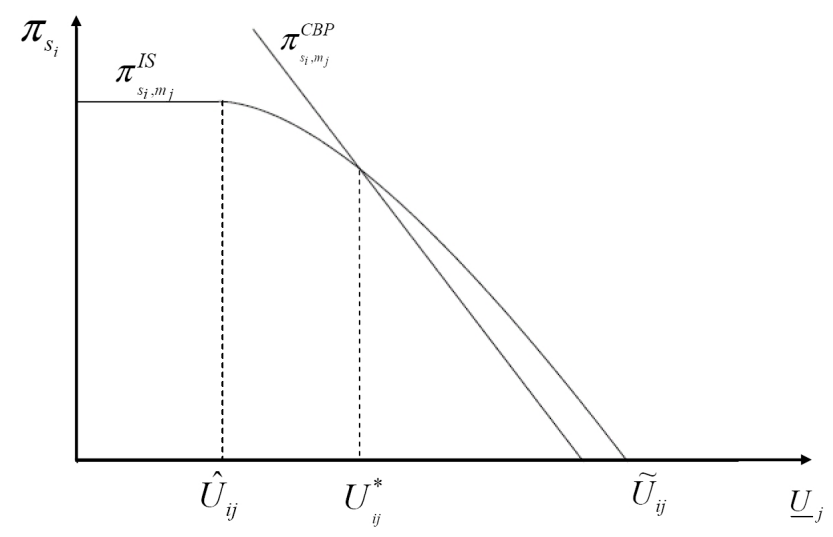

Figure 2: Adoption decision under good market conditions $(S r \geq \sqrt{3})$

The adoption of a CBP also depends on the ratio $R_{i} / c_{j}$, that is, on the value of the project and on the manager's efficiency. The higher this ratio, the higher the effort that will be asked from the manager; given the more acute agency problem, the shareholder $s_{i}$ finds the CBP more appealing. 


\section{Stable outcomes in the shareholder-manager mar- ket}

In this section, we analyze stable outcomes in this market. The main objectives are to highlight the effect of competition for managers on the contracts signed by firms and to identify the composition of the firms: who is matched with whom. First, we deal with the cases where all the agents on one of the two sides are homogeneous, i.e., either all the shareholders hold the same type of project or all the managers are equally efficient. We then provide properties of the stable outcomes in environments where both sides of the market are formed by heterogeneous agents. The existence of stable outcomes in our economy is well established by previous studies (see Kaneko, 1982). ${ }^{11}$ Remark 1 summarizes the existence of stable outcomes.

Remark 1 The set of stable outcomes in the market $\{\mathcal{S}, \mathcal{M}, \mathbf{R}, \mathbf{c}\}$ is always non-empty.

\subsection{Homogeneous shareholders and heterogeneous managers}

Consider the case where the projects in the hands of all the shareholders offer identical returns, i.e., $R_{i}=R$ for all $i=1, \ldots, n$ while the managers differ in their abilities, $c_{1}<$ $c_{2}<\ldots<c_{N}$. Denote by $m_{N}$ the least efficient manager with whom a shareholder makes non-negative profits (if there are less efficient managers in the market, we can discard them, as they will never be matched in a stable outcome).

Proposition 5 characterizes the stable outcomes in such a market. In the proposition, we denote by $\tilde{n}=\min \{n, N\}$ the number of firms that will be formed. We also introduce the following notation: if $S r>1$, we denote by $\underline{\pi}_{j}=\pi_{s}\left(W_{s, m_{j}}\left(U_{j}^{*}\right)\right)$ the level of profits that the shareholder obtains when manager $m_{j}$ 's utility is such that she is indifferent between a CBP contract and an IS contract. ${ }^{12}$ We note that $\underline{\pi}_{j}=\frac{R^{2}}{4 c_{j}}\left[\right.$ Var $\left.+\alpha^{2}\right]$ if $S r \in(1, \sqrt{3})$ and $\underline{\pi}_{j}=\frac{R^{2}}{c_{j}}\left[\sqrt{\operatorname{Var}\left(\operatorname{Var}+\alpha^{2}\right)}-\operatorname{Var}\right]$ if $S r \geq \sqrt{3}$. The level $\underline{\pi}_{j}$ decreases with $c_{j}$ (the inverse of manager's efficiency); hence it is also decreasing in $j$.

\footnotetext{
${ }^{11}$ Indeed, Kaneko (1982) generalizes the assignment game proposed by Shapley and Shubik (1972) and proves the non-emptiness of the core of this generalized version (see also Crawford and Knoer, 1981).

${ }^{12}$ For notational convenience, we denote $U_{j}^{*}$ instead of $U_{i j}^{*}$, since the shareholders are homogeneous.
} 
Proposition 5 When the shareholders are homogeneous and the managers are heterogeneous, properties (a) - (d) characterize an stable outcome $(\mu, \mathcal{W})$ for the market $\{\mathcal{S}, \mathcal{M}, \mathbf{R}, \mathbf{c}\}$ : (a) all shareholders have the same profit level $\pi$;

(b) $\pi=0$ if $n>N ; \pi \leq \pi_{s}\left(W_{s, m_{N}}(\underline{U})\right)$ if $n=N$; and $\pi \in\left[\pi_{s}\left(W_{s, m_{n+1}}(\underline{U})\right), \pi_{s}\left(W_{s, m_{n}}(\underline{U})\right)\right]$ if $n<N$;

(c) $W_{s, m_{j}}$ is the optimal contract for $m_{j}$ that gives profits $\pi$ to the shareholder.

In particular,

(d1) all the contracts are IS contracts if $S r \leq 1$ or if $S r>1$ and $\pi \leq \underline{\pi}_{\tilde{n}}$;

(d2) all the contracts are CBP contracts if $S r>1$ and $\pi>\underline{\pi}_{1}$;

(d3) $W_{s, m_{j}}$ is a CBP contract if $j>J$ and $W_{s, m_{j}}$ is an IS contract if $j \leq J$, when $S r>1$ and $J$ is such that $\underline{\pi}_{J} \geq \pi>\underline{\pi}_{J+1}$.

As Proposition 5 states, the set of stables outcomes is typically not a singleton when $\pi>0$. If $n=N$, then a stable outcome is associated to each $\pi \leq \pi_{s}\left(W_{s, m_{N}}(\underline{U})\right)$; hence, the set of stables outcomes is a singleton only when $\pi_{s}\left(W_{s, m_{N}}(\underline{U})\right)=0$. Similarly, if $n<N$ the set of stables outcomes is a singleton only when $c_{n}=c_{n+1}$, in which case $\pi_{s}\left(W_{s, m_{n+1}}(\underline{U})\right)=\pi_{s}\left(W_{s, m_{n}}(\underline{U})\right)$. Otherwise, a stable outcome can be associated to each $\pi$ in the interval.

We now explain the intuitions behind Proposition 5. Since all the shareholders hold projects with the same returns, their profits in stable outcomes must be equal. If this were not the case, shareholder $s_{i}$ obtaining lower profits than $s_{i^{\prime}}$ could attract manager $\mu\left(s_{i^{\prime}}\right)$ by proposing a contract that slightly increases his utility. Second, the level of profits depends on the strength of the competition for managers. Shareholders achieve positive profits when the competition for managers is smooth, that is, they are in the short side of the market. Furthermore, their profits are higher when there are very good unmatched managers. Third, in case (d1), all stable contracts are IS contracts if the ex-ante market conditions are not good enough, i.e., $S r \leq 1$. Also, if $S r>1$, all the contracts are still IS contracts when even the manager with the lowest ability among those matched, $m_{\tilde{n}}$, signs an IS contract. This may happen because either the shareholders are the long side of the market so that their equilibrium profits are zero, or the managers' outside utility $\underline{U}$ is high, or the level of ability of $m_{\tilde{n}}$ is low. Fourth, similarly, all stable contracts include a CBP if even the most efficient manager is offered a Code, which corresponds to markets with good ex-ante conditions $(S r>1)$ and where the shareholders' profits are high (case 
(d2)).

Finally, Proposition 5 (d3) describes the situations where IS and CBP contracts coexist: efficient managers end up being hired through IS contracts, while a CBP is used to attract inefficient ones. This contrasts with the conclusion obtained after Proposition 4, suggesting that a CBP would be adopted for efficient managers. When shareholders compete for the best managers, the conclusion is reversed. To attract efficient managers, shareholders offer them a high utility level and this now makes IS contracts more appealing than CBP contracts. This result stresses the relevance of the study of manager-shareholder relationships in a framework where not only the contracts but also the matching is endogenous. ${ }^{13}$

\subsection{Heterogeneous shareholders and homogeneous managers}

We now consider an economy formed by heterogeneous shareholders $\left(R_{i}>R_{i^{\prime}}\right.$ for all $\left.i<i^{\prime}\right)$ and equally efficient managers $\left(c_{j}=c\right.$ for all $\left.m_{j} \in \mathcal{M}\right)$. We denote by $s_{n}$ the shareholder endowed with the least profitable project that ensures non-negative profits; hence, $\tilde{n}=\operatorname{Min}\{N, n\}$ firms will be formed at a stable outcome. Proposition 6 characterizes the stable outcomes for this market (we denote $U_{i}^{*}$ instead of $U_{i j}^{*}$ ).

Proposition 6 When the shareholders are heterogeneous and the managers are homogeneous, then any stable outcome $(\mu, \mathcal{W})$ for the market $\{\mathcal{S}, \mathcal{M}, \mathbf{R}, \mathbf{c}\}$ is characterized by (a) a level $U^{o}$ that satisfies: $U^{o}=\underline{U}$ if $\tilde{n}<N, U^{o} \in\left[\widetilde{U}_{\tilde{n}+1, m}, \widetilde{U}_{\tilde{n}, m}\right]$ if $\tilde{n}=N<n$, and $U^{o} \in\left[\underline{U}, \widetilde{U}_{\tilde{n}, m}\right]$ if $\tilde{n}=N=n$

(b) all the contracts are $W_{s_{i}, m}=W_{s_{i}, m}\left(U^{o}\right)$;

In particular,

(c1) all the contracts are IS contracts if $S r \leq 1$ or if $S r>1$ and $U^{o} \geq U_{1}^{*}$;

(c2) all the contracts are CBP contracts if $S r>1$ and $U^{o}<U_{\tilde{n}}^{*}$;

(c3) $W_{s_{i}, m}$ is a CBP contract if $i \leq I$ and $W_{s_{i}, m}$ is an IS contract if $i>I$ if $S r>1$ and $U_{I+1}^{*} \leq U^{o}<U_{I}^{*}$

\footnotetext{
${ }^{13}$ As in the works of Barros and Macho-Stadler (1998) and Dam and Pérez-Castrillo (2006), the use of incentive contracts has also a positive effect on the firm's efficiency. The better the manager, the closer the effort to its First-Best level.
} 
Any stable outcome is characterized in part (b) of Proposition 6, once we know the managers' opportunity cost, as classified in part (a). A manager's opportunity cost is $\underline{U}$ if there are many managers. However, it is larger if there are at least as many shareholders as managers, for example because a manager has the possibility to build a firm with an unmatched shareholder. As happened in Proposition 5, the set of stables outcomes is typically not a singleton when $U^{o}>\underline{U}$. Indeed, a stable outcome is associated to each $U^{o} \in\left[\widetilde{U}_{\tilde{n}+1, m}, \widetilde{U}_{\tilde{n}, m}\right]$ if $\tilde{n}=N<n$, or $U^{o} \in\left[\underline{U}, \widetilde{U}_{\tilde{n}, m}\right]$ if $\tilde{n}=N=n$.

The proposition describes three different cases. Case (c1) identifies environments where the stable outcomes only involve IS contracts. This situation takes place in volatile markets or when the managers' opportunity cost is very high. Case (c2) considers environments with low variance and low cost for hiring managers, where all the contracts include a CBP. Case (c3) characterizes the circumstances under which both types of contracts coexist. The adoption decision in this framework is similar to the case of an isolated firm: shareholders who have good projects prefer to adopt a CBP, saving on incentive costs.

\subsection{Heterogeneous shareholders and heterogeneous managers}

We now analyze markets where both the shareholders and the managers are heterogeneous. The main question is whether shareholders with good projects end up hiring efficient managers. If this is a characteristic of the matching, we say it is positively assortative.

Definition 7 A matching $\mu$ for the market $\{\mathcal{S}, \mathcal{M}, \mathbf{R}, \mathbf{c}\}$ is positively assortative if shareholders with high-revenue projects are matched with efficient managers, i.e., $R_{i}>R_{i^{\prime}}$ implies that $c_{j} \leq c_{j^{\prime}}$, where $\mu\left(s_{i}\right)=m_{j}$ and $\mu\left(s_{i^{\prime}}\right)=m_{j^{\prime}}$.

Proposition 7 shows that stable outcomes do indeed always involve positively assortative matchings if all the firms find it optimal to use the same type of contract.

Proposition 7 If $(\mu, \mathcal{W})$ is a stable outcome for the market $\{\mathcal{S}, \mathcal{M}, \mathbf{R}, \mathbf{c}\}$, then $\mu$ is positively assortative if the contracts in $\mathcal{W}$ are all IS contracts, or they are all CBP contracts.

If, for instance, all participants hire managers through CBP contracts, then a negatively assortative contract could not be stable. The rationale is based on the fact that, for any given vector of managers' utilities, total profits are maximized when the best 
managers run the best projects. Therefore, any negative assortative matching would be blocked by at least one alternative shareholder-manager partnership that created more value for them.

However, the matching is not necessarily positively assortative when both types of contracts coexist. In that case, how does a non-positively assortative matching in a stable outcome look like? Proposition 8 describes such cases.

Proposition 8 If $(\mu, \mathcal{W})$ is a stable outcome for the market $\{\mathcal{S}, \mathcal{M}, \mathbf{R}, \mathbf{c}\}$ and if $\mu\left(s_{i}\right)=$ $m_{j}$ and $\mu\left(s_{i^{\prime}}\right)=m_{j^{\prime}}$ with $R_{i}>R_{i^{\prime}}$ and $c_{j}>c_{j^{\prime}}$, then $s_{i}$ and $m_{j}$ sign a CBP contract while $s_{i^{\prime}}$ and $m_{j^{\prime}}$ sign an IS contract.

Therefore, in a non-positively assortative matching in a stable outcome, shareholders with profitable projects hire low-ability managers through CBPs while high-ability managers sign incentive contracts in less profitable firms. Notice that the complementarity between shareholder's project and manager's efficiency implies that total output is higher when the matching is positively assortative. However, shareholders do not maximize total output but profits. Also, the better the shareholder, the more likely that she prefers to propose a CBP contract. Therefore, it may be that, shareholder $s_{2}$ 's best contract to attract manager $m_{1}$ is an IS contract, giving him a utility not lower than $\widehat{U}_{21}$, while a shareholder with a more profitable project, $s_{1}$, would prefer to hire this manager through a CBP. If $s_{1}$ is forced to pay $m_{1}$ the utility that $s_{2}$ is ready to offer, then she would rather attract a less efficient manager through a CBP, as long as the difference in efficiency between the two managers and in the value of the two projects is not too large. ${ }^{14}$

To illustrate the type of equilibria that can arise, let us consider the following numerical example. There are two shareholders with projects of value $R_{1}=2$ and $R_{2}=1$, and two managers, with cost parameters $c_{1}=10$ and $c_{2}=11$. The market conditions are characterized by $S r=\sqrt{2}$. Given the heterogeneity in both sides of the market, the set of stable outcomes is not a singleton. We characterize the most favorable stable outcome

\footnotetext{
${ }^{14}$ Legros and Newman (2007) provide conditions under which a positive assortative matching is attained (see also Legros and Newman, 2002). Complementarity in partner's types is a condition required for a positive assortative matching to arise. However, another condition needs to be satisfied: the willingness to pay of the best shareholder to hire the best manager should increase with the value of the project. This is not necessarily the case when there is a choice between different governance structures, namely CBP or IS.
} 
for the shareholders. In this outcome, manager $m_{2}$ can be hired at the cost of $\underline{U}$ while the level of utility of $m_{1}$ will be determined by the value of this manager for the shareholder hiring $m_{2}$.

Consider a positive assortative candidate outcome: $\mu\left(s_{1}\right)=m_{1}$ and $\mu\left(s_{2}\right)=m_{2}$. Manager $m_{1}$ 's utility $U^{1}(\underline{U})$ at this outcome is characterized by the maximum utility that $s_{2}$ is ready to offer to this manager to hire him instead of $m_{2}$, that is, $U^{1}(\underline{U})$ is implicitly defined by $\pi_{s_{2}}\left(W_{s_{2}, m_{2}}(\underline{U})\right)=\pi_{s_{2}}\left(W_{s_{2}, m_{1}}\left(U^{1}(\underline{U})\right)\right)$. Given the two "equilibrium" managers' utility levels, Figure 3 plots shareholder $s_{1}$ 's profits when she hires $m_{1}$ at a cost of $U^{1}(\underline{U})$ (solid line) and her profits when she hires $m_{2}$ at a cost of $\underline{U}$ (dotted line).

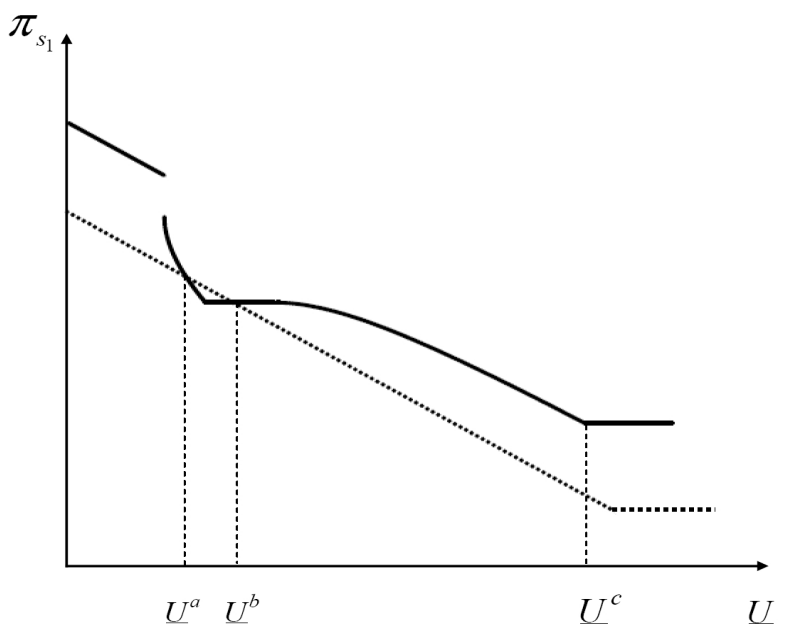

Figure 3: Shareholder $s_{1}$ 's profits

According to Figure 3, the positive assortative matching $\mu$ together with contracts $W_{s_{1}, m_{1}}\left(U^{1}(\underline{U})\right)$ and $W_{s_{2}, m_{2}}(\underline{U})$ constitute a stable outcome for $\underline{U} \in\left[0, \underline{U}^{a}\right] \cup\left[\underline{U}^{b}, \underline{U}^{c}\right] \cup$ $\left[\underline{U}^{c}, \underline{U}^{\max }\right]$. In the first interval, both contracts include CBPs, since managers' utility levels are low, while both are IS contracts in the interval $\left[\underline{U}^{c}, \underline{U}^{\max }\right]$, where managers obtain high utility levels. ${ }^{15}$ In the interval $\left[\underline{U}^{b}, \underline{U}^{c}\right]$, where the outside utility takes intermediate values, shareholder $s_{1}$ still uses CBPs, while $s_{2}$ finds it optimal to give manager $m_{2}$ incentives. Hence, both types of contract coexist in a market where the matching is positively assortative. However, another type of stable outcome exists in the interval

\footnotetext{
${ }^{15}$ The jump in the first interval happens at the outside utility level where $s_{2}$ would start hiring $m_{1}$ through an IS contract, so $U^{1}(\underline{U})$ jumps upwards and $\pi_{s_{1}}\left(W_{s_{1}, m_{1}}\left(U^{1}(\underline{U})\right)\right)$ jumps downwards at this level.
} 
$\left(\underline{U}^{a}, \underline{U}^{b}\right)$ where shareholder $s_{1}$ and manager $m_{2}$ sign a contract including CBPs. In fact, in this region of parameters, the non-positive assortative matching $\mu^{\prime}\left(s_{1}\right)=m_{2}$ and $\mu^{\prime}\left(s_{2}\right)=m_{1}$ with the contracts $W_{s_{1}, m_{2}}(\underline{U})$ (a CBP contract) and $W_{s_{2}, m_{1}}\left(U^{1 \prime}(\underline{U})\right.$ ) (an IS contract) is indeed the shareholders' best stable outcome, where $U^{1 \prime}(\underline{U})$ is lower than $U^{1}(\underline{U})$, and it is characterized by shareholder $s_{1}$ 's willingness to pay for $m_{1}$, that is, $\pi_{s_{1}}\left(W_{s_{1}, m_{2}}(\underline{U})\right)=\pi_{s_{1}}\left(W_{s_{1}, m_{1}}\left(U^{1 \prime}(\underline{U})\right)\right)$.

\section{Introducing Codes: Welfare Considerations}

As we have stressed, CBPs are voluntary mechanisms; shareholders only adopt them if they earn higher profits, given the managers' utilities. Therefore, a welfare improvement, that is, a higher sum of shareholders' expected profits and managers' expected utilities, is to be expected if shareholders choose to implement CBPs. However, this is not always be the case due to three effects. First, CBPs allow shareholders to save on incentive costs when IS contracts lead to managers' utility levels higher than their reservation utility. Hence, they may be willing to adopt CBPs even if they are welfare decreasing. Second, the introduction of Codes may have an effect on the managers' utility levels. Finally, it may also have a deep effect on the market structure, giving rise to a negative assortative matching.

Given that the set of stable outcomes in this economy is not necessarily unique, in general it is difficult to derive a comparative statics analysis for welfare. Nonetheless, we are still able to draw appealing welfare implications from analyzing particular market conditions. Note that we do not discuss those environments that forecast low market conditions $(S r \leq 1)$ since firms operating in these environments will never adopt CBPs.

We start with the discussion of the welfare of a firm $\left(s_{i}, m_{j}\right)$ when the manager's reservation utility $\underline{U}_{j}$ is kept fixed, as a function of the governance mechanism:

$$
\mathcal{S} \mathcal{W}_{i j}^{C B P}=\frac{\alpha^{2}}{2} \frac{R_{i}^{2}}{c_{j}} \text { and } \mathcal{S} \mathcal{W}_{i j}^{I S}=\left\{\begin{array}{ll}
\frac{3\left[\operatorname{Var}+\alpha^{2}\right]}{8} \frac{R_{i}^{2}}{c_{j}} & \text { if } \underline{U}_{j}<\widehat{U}_{i j} \\
R_{i} \sqrt{\frac{2\left[\operatorname{Var}+\alpha^{2}\right]}{c_{j}}}-\underline{U}_{j} & \text { if } \underline{U}_{j} \geq \widehat{U}_{i j}
\end{array} .\right.
$$

Consider first the case when manager's utility is large, i.e., $\underline{U}_{j} \geq \widehat{U}_{i j}$. Then the Code is only adopted when $S r>\sqrt{3}$ (because $U_{i j}^{*} \leq \widehat{U}_{i j}$ whenever $S r \leq \sqrt{3}$ ) and, if adopted (i.e., if $\underline{U}_{j}<U_{i j}^{*}$ ), it is always the case that $\mathcal{S} \mathcal{W}_{i j}^{C B P}>\mathcal{S} \mathcal{W}_{i j}^{I S}$. The reason for 
this property is that the manager's utility does not vary and the shareholder's profits increase. Second, if the manager's utility is low (i.e., $\underline{U}_{j}<\widehat{U}_{i j}$ ), then $\mathcal{S} \mathcal{W}_{i j}^{C B P}>\mathcal{S} \mathcal{W}_{i j}^{I S}$ if and only if $S r>\sqrt{3}$ : the shareholder increases profits in all markets where $S r>1$, but the manager's utility falls from $\widehat{U}_{i j}$ to $\underline{U}_{j}$. Introducing Codes is welfare improving only if $S r>\sqrt{3}$, where the increase in profits outweighs the fall in utility, while otherwise the total welfare is reduced. Therefore, for a given partnership $\left(s_{i}, m_{j}\right)$ and utility $\underline{U}_{j}$, the possibility of adopting a CBP is welfare improving if and only if the market condition forecast is high, i.e., $\mathrm{Sr}>\sqrt{3} .^{16}$

The previous analysis shows the implications for welfare of the introduction of CBPs in markets where there is no real interaction among shareholders, in the sense that the decision any of them makes is not affected by the others. This is the case, in particular, in markets with many homogeneous managers, where any shareholder can always hire one of them at a cost of $\underline{U}$.

Proposition 9 When the market is composed by heterogeneous shareholders and homogeneous managers and $N>n$, the introduction of Codes improves welfare if and only if $\operatorname{Sr}>\sqrt{3}$.

In markets with few homogeneous managers, i.e., $N \leq n$, the set of stable outcomes is not necessarily unique, see Proposition 6; each of them is characterized by the level of managers' utility $U^{o}$. However, one convenient feature is that the interval of such "stable utility levels" is the same when CBPs are possible and when only IS contracts can be signed. This property allows us to formulate the following simple extension of the previous proposition:

Proposition 10 Suppose that the market is composed of heterogeneous shareholders and homogeneous managers and that $N \leq n$. Consider the stable outcome $\left(\mu, \mathcal{W}^{I S}\right)$ when only IS contracts are allowed, and let $U^{o}$ be the level of managers' utility that characterizes this outcome. Let $(\mu, \mathcal{W})$ be the stable outcome (when CBPs are possible) that is characterized by the same $U^{o}$. Then, the total welfare under $(\mu, \mathcal{W})$ is higher than total welfare under $\left(\mu, \mathcal{W}^{I S}\right)$ if and only if $S r>\sqrt{3} \cdot{ }^{17}$

\footnotetext{
${ }^{16}$ We say that Codes are welfare improving if their introduction can never decrease welfare and they increase it whenever they are actually signed.

${ }^{17}$ Notice the one particular situation where the the set of stable outcomes is a singleton; hence Propo-
} 
In markets composed of homogeneous shareholders and heterogeneous managers, some new effects arise. As seen in Proposition 5, a stable outcome is characterized by the level of shareholders' profits $\pi$. When there are many shareholders, i.e., $n>N$, the profits vanish to zero and no firm will sign a CBP contract; hence, its introduction has no effect.

When the number of homogeneous shareholders is not larger than the number of heterogeneous managers, i.e., $n \leq N$, we also face a problem of multiplicity of stable outcomes. The added difficulty now is that the interval of "stable profits levels" is different when CBPs are introduced than when they are not: the boundaries of the interval are higher when Codes can be offered. Shareholders may earn more profits when they can offer CBPs, sometimes by reducing manager's utility. Therefore, the introduction of CBPs affects the utility not only of the managers hired by firms implementing CBPs, but also of the rest of the managers. Given that a decrease in manager's utility leads to a lower effort under an IS contract, this additional effect is typically negative for welfare.

A final effect of the introduction of CBPs is that the matching may not longer be positively assortative if both types of contract coexist. This effect is also typically detrimental for welfare, since a higher output is obtained under a positively assortative matching.

Therefore, the introduction of CBPs is likely to worsen welfare in those environments where market conditions forecasts are moderate $(\operatorname{Sr} \in(1, \sqrt{3}])$. On the other hand, in environments where forecasts are high $(S r>\sqrt{3})$, the introduction of CBPs is likely to have positive effects on welfare as long as it does not induce too many changes in the structure of the market, either through drastic decreases in managers' levels of utility or through changes in the equilibrium allocation of managers to firms.

\section{Conclusion and Extensions}

This paper has explored the way market conditions and competition affects shareholders' willingness to adopt Codes of Best Practice. We have modeled a Code as a monitoring mechanism that allows shareholders to control the managers' decisions ex-ante. Adopting the Code, however, impedes the managers' flexible reaction to changing market conditions.

sition 10 can be written in the same terms as Proposition 9, is a market with at least $N+1$ shareholders, where $R_{N}=R_{N+1}$. In this market, the level of $U^{o}$ that characterizes the unique stable outcome is defined as the level that makes shareholder $N$ 's profits equal to zero. 
CBPs tend to be adopted in environments where predicting the market conditions is not a complex task for shareholders. More mature industries, such as the utilities, banking and food and drink sectors, should be, according to our predictions, examples of industries where CBPs are more likely to be adopted. On the other hand, when the environment faces high volatility, the best option for a shareholder is to leave the manager's hands free, i.e., to offer him an incentive contract. High-tech sectors such as dot-com industries or pharmaceutical companies should tend to use incentive contracts, letting the manager take the major decisions.

Our analysis may have implications regarding when firms will be more willing to adopt CBPs. Indeed, market conditions vary depending, for instance, on macroeconomic conditions or business cycles. As we have mentioned, the choice of the governance structure takes into account the expected market conditions, measured through the Sharpe ratio. CBPs are more likely to be adopted after recessions, when expected market conditions tend to improve, whereas contracts based on incentives should be expected during (or at the end of) booms where forecasts for market conditions tend to worsen.

Our findings suggest that the characteristics of the set of shareholders and the set of managers in the market have deep effects on the decision of whether to adopt a CBP. When the shareholders have similar projects, i.e., the firms' technologies are similar, then CBPs do not seem to be the right mechanisms to attract the best managers. Indeed, when both types of governance structures coexist, the lower the manager's ability, the more likely that a Code is adopted. Instead, when managers are of similar ability, the shareholders with the best projects prefer to adopt the Code to reduce manager's rents. In fact, our analysis suggests that the best shareholders might be willing to renounce hiring the best managers, who would be offered incentive contracts, and hire instead lower ability managers through CBPs. Hence, although the matching between shareholders and managers is always positively assortative when only one type of governance structure exists in the market, the property may fail to hold due to the coexistence of both governance structures.

Since the characteristics of the market are linked to the type of industry a firm operates in and to the type of project it conducts, it seems natural to ask how the conclusions of our analysis would be affected if shareholders' heterogeneity was not due to the value of their project but to the distribution function of the market-specific characteristics (that 
is, we would have a distribution function $F_{i}(h)$ for each shareholder $s_{i}$ ). Also in this case, matching is "positively assortative" when all firms end up under the same type of governance structure. However, the meaning of "positively assortative" depends now on the type of governance. If all contracts include a Code, then the best managers are hired by those shareholders whose market-specific component has a higher mean. However, if they are all incentive contracts, the "best" shareholders are those in markets where the combination of mean and variance (expressed in the variable $\operatorname{Var}+\alpha^{2}$ ) is higher; these are the shareholders who end up forming firms with the higher-ability managers. Also, we have some information about what a non-positively assortative matching in a stable outcome looks like. For example, if all shareholders own projects in markets whose shocks have the same average, then in a non-positively assortative matching, shareholders in markets with higher volatility hire low-ability managers through incentive contracts while high-ability managers sign contracts including a Code in firms producing in markets with lower variance.

Finally, we have not considered the possibility that firms, once created, could compete against each other in the product market. In our model, there was competition among shareholders to catch the best managers and among managers to get the best contracts, but there was no competition among firms. A firm's profits were independent of the composition of the other firms. Extending our model to explicitly allow firms' market competition seems computationally demanding. However, the analysis developed so far provides enough elements to be able to anticipate the effects of firms' competition on the use of Codes of Best Practices.

For our purposes, market competition among firms should have two main implications. First, it makes the best managers even more appealing than before as shareholders will be ready to offer good salaries to them not only because of their value for the firm but also to prevent them from hired by the market competitors. According to our results, such an increase in managers' utility should favor the use of incentive contracts. Second, market competition typically allows the improvement of incentive contracts by making use of yardstick contracts, where a manager is paid not only according to his absolute performance, but also as a function of his relative performance with respect to others. Both effects act to make incentive contracts more appealing. Therefore, we should expect to observe less use of Codes in those markets characterized by tough competition. 


\section{Appendix}

Proof of Proposition 1. Assume that $(\mu, \mathcal{W})$ is stable. (a) If there exists a feasible $W^{\prime}$ for $\left(s_{i}, m_{j}=\mu\left(s_{i}\right)\right)$ such that $\pi_{s_{i}}\left(m_{j}, W^{\prime}\right) \geq \pi_{s_{i}}\left(m_{j}, W_{s_{i}, m_{j}}\right)$ and $V_{m_{j}}\left(s_{i}, W^{\prime}\right)=$ $V_{m_{j}}\left(s_{i}, W_{m_{j}, s_{i}}\right)$, then consider the contract $W^{\prime \prime}$ that includes both salaries higher than $W^{\prime}$ by $\epsilon>0$. The managers' efforts are the same under $W^{\prime \prime}$ and $W^{\prime}$ (if they include a CBP, this will happen by contract; if they are IS contracts, the ICC does not change). If $\epsilon$ is small enough, then $\pi_{s_{i}}\left(m_{j}, W^{\prime \prime}\right)>\pi_{s_{i}}\left(m_{j}, W_{s_{i}, m_{j}}\right)$ and $V_{m_{j}}\left(s_{i}, W^{\prime \prime}\right)>V_{m_{j}}\left(s_{i}, W_{m_{j}, s_{i}}\right)$, which would contradict the stability of $(\mu, \mathcal{W})$.

(b) If there exists a feasible $W^{\prime}$ for $\left(s_{i}, m_{j}\right)$ including a CBP such that $\pi_{s_{i}}\left(m_{j}, W^{\prime}\right)=$ $\pi_{s_{i}}\left(m_{j}, W_{s_{i}, m_{j}}\right)$ and $V_{m_{j}}\left(s_{i}, W^{\prime}\right)>V_{m_{j}}\left(s_{i}, W_{m_{j}, s_{i}}\right)$, then the contract $W^{\prime \prime}$ with both salaries lower that $W^{\prime}$ by a small enough $\epsilon>0$ satisfies $\pi_{s_{i}}\left(m_{j}, W^{\prime \prime}\right)>\pi_{s_{i}}\left(m_{j}, W_{s_{i}, m_{j}}\right)$ and $V_{m_{j}}\left(s_{i}, W^{\prime \prime}\right)>V_{m_{j}}\left(s_{i}, W_{m_{j}, s_{i}}\right)$. If $W^{\prime}$ is an IS contract, then the proof requires properties that we study later on. In Proposition 2, we characterize the set of optimal contracts for a shareholder under the (weak inequality) constraint that her manager obtains a certain level of utility; that is, we only use the optimality property that we have just shown in (a). The set of feasible utility-profits pairs that can be achieved under IS contracts satisfies two properties: there is only one contract that achieves the highest level of shareholder's profits (where $m_{j}$ obtains the utility level that we will denote $\widehat{U}_{i j}$ ) and the frontier of utility-profits pairs is strictly decreasing from that point on. Therefore, if there exists $W^{\prime}$ providing higher utility for $m_{j}$ than $W_{m_{j}, s_{i}}$, it is necessarily the case that $W_{m_{j}, s_{i}}$ provides $s_{i}$ with a level of profits lower than the maximum level, and thus it does not lie in the Pareto frontier. Hence, there also exists $W^{\prime \prime}$ that strictly improves both shareholder $s_{i}$ 's profits and manager $m_{j}$ 's utility, which would contradict the stability of $(\mu, \mathcal{W})$.

Proof of Proposition 2. The contract $W_{s_{i}, m_{j}}^{I S}\left(\underline{U}_{j}\right)$ is the solution to the program

$$
\begin{gathered}
\max _{\left\{w_{i, j}^{R}, w_{i, j}^{0}, e_{i, j}\right\}} \int_{\underline{h}}^{\bar{h}}\left\{h e_{i, j}\left(w_{i, j}^{R}, w_{i, j}^{0} ; h\right)\left[R_{i}-w_{i, j}^{R}\right]-\left[1-h e_{i, j}\left(w_{i, j}^{R}, w_{i, j}^{0} ; h\right)\right] w_{0}\right\} d F(h) \\
\text { s.t. }(I C C),\left(L L_{R}\right),\left(L L_{0}\right), \text { and } \\
\int_{\underline{h}}^{\bar{h}}\left\{h e_{i, j}\left(w_{i, j}^{R}, w_{i, j}^{0} ; h\right) w_{i, j}^{R}+\left[1-h e_{i, j}\left(w_{i, j}^{R}, w_{i, j}^{0} ; h\right)\right] w_{i, j}^{0}-c_{j} \frac{e_{i, j}\left(w_{i, j}^{R}, w_{i, j}^{0} ; h\right)^{2}}{2}\right\} d F(h) \geq \underline{U}_{j} .
\end{gathered}
$$


We can rewrite the programme by plugging $(I C C)$ into the objective function and the last constraint and set $\theta \equiv \operatorname{Var}+\alpha^{2}$. After some calculations, we obtain

$$
\begin{gathered}
\max _{\left\{w_{i, j}^{R}, w_{i, j}^{0}\right\}}\left\{-w_{i, j}^{0}+\frac{\theta}{c_{j}}\left(w_{i, j}^{R}-w_{i, j}^{0}\right)\left(R_{i}-\left(w_{i, j}^{R}-w_{i, j}^{0}\right)\right)\right\} \\
\text { s.t. } w_{i, j}^{0}+\frac{\theta}{2 c_{j}}\left(w_{i, j}^{R}-w_{i, j}^{0}\right)^{2} \geq \underline{U}_{j} \\
w_{i, j}^{0} \geq 0 .
\end{gathered}
$$

where we have omitted $\left(L L_{R}\right)$ since it is implied by $(I C C)$ and $(2)$.

Let $\lambda$ and $\rho$ be the Lagrange multipliers corresponding to (1) and (2), respectively. The Kuhn-Tucker (first-order) conditions of the above maximization problem are (1), (2), $\lambda \geq 0, \rho \geq 0$, and

$$
\begin{gathered}
\frac{\theta}{c_{j}}\left(R_{i}-2\left(w_{i, j}^{R}-w_{i, j}^{0}\right)\right)+\lambda \frac{\theta}{c_{j}}\left(w_{i, j}^{R}-w_{i, j}^{0}\right)=0 \\
-1-\frac{\theta}{c_{j}}\left(R_{i}-2\left(w_{i, j}^{R}-w_{i, j}^{0}\right)\right)+\lambda-\lambda \frac{\theta}{c_{j}}\left(w_{i, j}^{R}-w_{i, j}^{0}\right)+\rho=0 \\
\lambda\left[w_{i, j}^{0}+\frac{\theta}{2 c_{j}}\left(w_{i, j}^{R}-w_{i, j}^{0}\right)^{2}-\underline{U}_{j}\right]=0 \\
\rho w_{i, j}^{0}=0 .
\end{gathered}
$$

First, simplifying (3) we get

$$
\lambda=2-\frac{R_{i}}{\left(w_{i, j}^{R}-w_{i, j}^{0}\right)}
$$

and plugging (6) into (4) we obtain

$$
\rho=-1+\frac{R_{i}}{\left(w_{i, j}^{R}-w_{i, j}^{0}\right)} .
$$

We study the different regions where the Kuhn-Tucker conditions may be satisfied:

Case 1: $\lambda>0, \rho>0$ (Both (1) and (2) are binding). The payment in case of failure is $w_{i, j}^{0}=0$ following (1) while in case of success it is $w_{i, j}^{R}=\sqrt{\frac{2 \underline{U}_{j} c_{j}}{\theta}}$ from (2). Finally, from (6) and (7), $\lambda>0$ and $\rho>0$ are possible only if $\underline{U}_{j} \in\left(\frac{R_{i}^{2}}{c_{j}} \frac{\theta}{8}, \frac{R_{i}^{2}}{c_{j}} \frac{\theta}{2}\right)$.

Case 2: $\lambda=\rho=0$. (3) implies $R_{i}=2\left(w_{i, j}^{R}-w_{i, j}^{0}\right)$ and plugging this into (4) we get $-1=0$, which is not possible.

Case 3: $\lambda>0, \rho=0\left((1)\right.$ is binding). From (7) we get $w_{i, j}^{R}-w_{i, j}^{0}=R_{i}$. This implies that $\lambda=1$. Then, (1) implies $w_{0}=\underline{U}_{j}-\frac{R_{i}^{2}}{c_{j}} \frac{\theta}{2}$. Since $w_{0} \geq 0$, this case is only possible if $\underline{U}_{j} \geq \frac{R_{i}^{2}}{c_{j}} \frac{\theta}{2}$. 
Case 4: $\lambda=0, \rho>0\left((2)\right.$ is binding). From (2) we obtain $w_{0}=0$, and using (6), we get $w_{R}=\frac{R_{i}}{2}$. This implies, by (7), $\rho=1$. In this case (1) holds only if $\underline{U}_{j} \leq \frac{R_{i}^{2}}{c_{j}} \frac{\theta}{8}$.

If $\underline{U}_{j}>\frac{R_{i}^{2}}{c_{j}} \frac{\theta}{2}$, the optimum must lie in Case 3 and $\pi_{s_{i}}=-w_{i, j}^{0}<0$, which is not feasible. If $\underline{U}_{j}<\frac{R_{i}^{2}}{c_{j}} \frac{\theta}{8}$, the optimum lies in Case 4, where $U_{j}=\frac{R_{i}^{2}}{c_{j}} \frac{\theta}{8}$ and the shareholder's profits are the same as if $\underline{U}_{j}=\frac{R_{i}^{2}}{c_{j}} \frac{\theta}{8}$. These facts prove part (a) in Proposition 2.

Also, it is easily checked that the solution at the borders of Cases 3 and 4 coincide with the solution at the borders of Case 1 (the solution is continuous). Therefore, the optimal contract has the shape found in Case 1, which proves part (b). Finally, parts (c) and (d) follow from the contracts in Case 1.

Proof of Proposition 3. First, a fixed wage is optimal, we denote it by $w_{i, j}$ $\left(=w_{i, j}^{R}=w_{i, j}^{0}\right)$. The contract $W_{s_{i}, m_{j}}^{C B P}\left(\underline{U}_{j}\right)$ is the solution to the program

$$
\begin{gathered}
\max _{\left\{e, w_{i, j}\right\}} \int_{\underline{h}}^{\bar{h}} h e R_{i} d F(h)-w_{i, j}=\alpha e R_{i}-w_{i, j} \\
\text { s.t. } w_{i, j}-c_{j} \frac{e^{2}}{2} \geq \underline{U}_{j} \\
w_{i, j} \geq 0 .
\end{gathered}
$$

From (8), we get $w_{i, j} \geq c_{j} \frac{e^{2}}{2}+\underline{U}_{j}$, which implies that (9) is not binding. Also, since $w_{i, j}$ negatively affects shareholder $s_{i}$ 's expected profits, (8) is binding. This proves part (c) of Proposition 3. Therefore, the shareholder's problem is

$$
e_{i, j}^{C B P} \in \arg \max _{e_{i, j}}\left\{\alpha e R_{i}-c_{j} \frac{e^{2}}{2}\right\}
$$

hence, $e_{i, j}^{C B P}=\frac{R_{i}}{c_{j}} \alpha$. This shows part (a). Part (b) is obtained by plugging $e_{i, j}^{C B P}$ into (8) binding. Finally, to prove part $(d)$, we substitute $e_{i, j}^{C B P}$ and the optimal wage into shareholder $s_{i}$ 's expected profits.

Proof of Proposition 4. We compare the profit functions of propositions 2 and 3. First, we compare both profit functions at the extreme values $\underline{U}_{j}=0$ and $\widetilde{U}_{i j}$ :

$$
\begin{gathered}
\pi_{s_{i}}\left(W_{s_{i}, m_{j}}^{C B P}(0)\right) \leq \pi_{s_{i}}\left(W_{s_{i}, m_{j}}^{I S}(0)\right) \Longleftrightarrow \frac{R_{i}^{2}}{c_{j}} \frac{\alpha^{2}}{2} \leq \frac{R_{i}^{2}}{c_{j}} \frac{\left[\operatorname{Var}+\alpha^{2}\right]}{4} \Longleftrightarrow \text { Var } \geq \alpha^{2} . \\
\pi_{s_{i}}\left(W_{s_{i}, m_{j}}^{C B P}\left(\widetilde{U}_{i j}\right)\right)=\frac{R_{i}^{2}}{c_{j}} \frac{\alpha^{2}}{2}-\frac{R_{i}^{2}}{c_{j}} \frac{\left[\operatorname{Var}+\alpha^{2}\right]}{2}<0=\pi_{s_{i}}\left(W_{s_{i}, m_{j}}^{I S}\left(\widetilde{U}_{i j}\right)\right),
\end{gathered}
$$


Moreover, $\frac{\partial\left(\pi_{s_{i}}\left(W_{s_{i}, m_{j}}^{C B P}\left(\underline{U}_{j}\right)\right)\right)}{\partial \underline{U}_{j}}=-1, \frac{\partial\left(\pi_{s_{i}}\left(W_{s_{i}, m_{j}}^{I S}\left(\underline{U}_{j}\right)\right)\right)}{\partial \underline{U}_{j}}=0$ for $\underline{U}_{j} \leq \widehat{U}_{i j}$, and $\pi_{s_{i}}\left(W_{s_{i}, m_{j}}^{I S}\left(\underline{U}_{j}\right)\right)$ is a decreasing and concave function of $\underline{U}_{j}$ for $\underline{U}_{j} \in\left[\widehat{U}_{i j}, \widetilde{U}_{i j}\right]$ with $\frac{\partial\left(\pi_{s_{i}}\left(W_{s_{i}, m_{j}}^{I S}\left(\underline{U}_{j}\right)\right)\right)}{\partial \underline{\underline{U}}_{j}}=$ 0 for $\underline{U}_{j}=\widehat{U}_{i j}$ and $\frac{\left.\partial\left(\pi_{s_{i}}\left(W_{s_{i}, m_{j}}^{I S} \underline{U}_{j}\right)\right)\right)}{\partial \underline{\underline{U}}_{j}}=-1$ for $\underline{U}_{j}=\widetilde{U}_{i j}$. Therefore, the functions $\pi_{s_{i}}\left(W_{s_{i}, m_{j}}^{C B P}\left(\underline{U}_{j}\right)\right)$ and $\pi_{s_{i}}\left(W_{s_{i}, m_{j}}^{I S}\left(\underline{U}_{j}\right)\right)$ cross at most once in $\left[0, \widetilde{U}_{i j}\right]$.

The previous properties imply, first of all, that $\pi_{s_{i}}\left(W_{s_{i}, m_{j}}^{C B P}\left(\underline{U}_{j}\right)\right) \leq \pi_{s_{i}}\left(W_{s_{i}, m_{j}}^{I S}\left(\underline{U}_{j}\right)\right)$ for all $\underline{U}_{j}$ if $\operatorname{Var} \geq \alpha^{2}$. Second, $\pi_{s_{i}}\left(W_{s_{i}, m_{j}}^{I S}\left(\underline{U}_{j}\right)\right)=\frac{R_{i}^{2}}{c_{j}} \frac{\left[\operatorname{Var}+\alpha^{2}\right]}{4}$ for all $\underline{U}_{j} \leq \widehat{U}_{i j}$ and $\pi_{s_{i}}\left(W_{s_{i}, m_{j}}^{C B P}\left(\underline{U}_{j}\right)\right)$ is strictly decreasing w.r.t. $\underline{U}_{j}$. We evaluate the profits at $\widehat{U}_{i j}$ and obtain

$$
\begin{aligned}
\pi_{s_{i}}\left(W_{s_{i}, m_{j}}^{C B P}\left(\widehat{U}_{i j}\right)\right) & \leq \pi_{s_{i}}\left(W_{s_{i}, m_{j}}^{I S}\left(\widehat{U}_{i j}\right)\right) \Longleftrightarrow \frac{R_{i}^{2}}{c_{j}} \frac{\alpha^{2}}{2}-\frac{R_{i}^{2}}{c_{j}} \frac{\left[\operatorname{Var}+\alpha^{2}\right]}{8} \leq \frac{R_{i}^{2}}{c_{j}} \frac{\left[\operatorname{Var}+\alpha^{2}\right]}{4} \\
& \Longleftrightarrow \alpha^{2} \leq \frac{3}{4}\left[\operatorname{Var}+\alpha^{2}\right] \Longleftrightarrow \operatorname{Var} \geq \frac{1}{3} \alpha^{2} .
\end{aligned}
$$

Therefore, if $S r \in[1, \sqrt{3}]$ the Code is adopted if and only if $\underline{U}_{j}<U_{i j}^{*}$, where $U_{i j}^{*} \in\left[0, \widehat{U}_{i j}\right]$ is defined by $\pi_{s_{i}}\left(W_{s_{i}, m_{j}}^{C B P}\left(U_{i j}^{*}\right)\right)=\pi_{s_{i}}\left(W_{s_{i}, m_{j}}^{I S}\left(U_{i j}^{*}\right)\right)$, i.e., $U_{i j}^{*}=\frac{R_{i}^{2}}{2 c_{j}}\left[\frac{\alpha^{2}-V a r}{2}\right]$.

Finally, if $S r \geq \sqrt{3}$, then $\pi_{s_{i}}\left(W_{s_{i}, m_{j}}^{C B P}\left(\widehat{U}_{i j}\right)\right)>\pi_{s_{i}}\left(W_{s_{i}, m_{j}}^{I S}\left(\widehat{U}_{i j}\right)\right)$ and $\pi_{s_{i}}\left(W_{s_{i}, m_{j}}^{C B P}\left(\widetilde{U}_{i j}\right)\right)<$ $\pi_{s_{i}}\left(W_{s_{i}, m_{j}}^{I S}\left(\widetilde{U}_{i j}\right)\right)$. By the properties of the derivatives of the profit functions, there exists a unique $U_{i j}^{*} \in\left(\widehat{U}_{i j}, \widetilde{U}_{i j}\right)$ such that the Code is adopted if $\underline{U}_{j}<U_{i j}^{*}$. Level $U_{i j}^{*}$ is the smallest of the two values for which $\pi_{s_{i}}\left(W_{s_{i}, m_{j}}^{C B P}\left(U_{i j}^{*}\right)\right)=\pi_{s_{i}}\left(W_{s_{i}, m_{j}}^{I S}\left(U_{i j}^{*}\right)\right)$, i.e., $R_{i} \sqrt{\frac{2\left[\operatorname{Var}+\alpha^{2}\right] U_{i j}^{*}}{c_{j}}}-$ $2 U_{i j}^{*}=\frac{R_{i}^{2}}{c_{j}} \frac{\alpha^{2}}{2}-U_{i j}^{*}$. It corresponds to the expression stated in the Proposition.

Proof of Proposition 5. Part (a) is necessary: if shareholder $s_{1}$ would obtain lower profits than $s_{2}$, then she could hire $\mu\left(s_{2}\right)$ by offering him a slightly better utility level than before and make strictly higher profits. Part (b) easily follows from the maximum and minimum profits that the shareholder hiring the worst manager (or not hiring at all) can make. Part (c) follows after Proposition 1. Finally, it is immediate that if the contracts satisfy (a) - (c), then the outcome is stable.

To prove part (d1), we note that if $S r \leq 1$, the CBP is never adopted according to Proposition 4. If $S r>1$ and $\pi \leq \underline{\pi}_{n}$, then $\pi \leq \underline{\pi}_{j}$ for all $m_{j}$, since $\underline{\pi}_{j}$ is decreasing in $j$. This implies that $U_{j} \geq U_{j}^{*}$, since the constrained Pareto optimal contract between the shareholder and $m_{j}$ that provides her a profit level smaller or equal than $\underline{\pi}_{j}$ shall give $m_{j}$ higher utility level than $U_{j}^{*}$ (which he would obtain if the shareholder would get $\underline{\pi}_{j}$ ). Therefore (Proposition 4), an incentive contract is optimal for all $j$. A very similar argument allows us to prove (d2). When $S r>1$ and $J$ is such that $\underline{\pi}_{J} \geq \pi>\underline{\pi}_{J+1}$ 
then $\underline{\pi}_{J} \geq \pi$ if and only if $j \leq J$. As we have argued above, $\underline{\pi}_{j} \geq \pi$ implies that the constrained Pareto optimal contract between a shareholder and $m_{j}$ is an IS contract. In fact, $W_{s, m_{j}}$ is a IS contract if and only if $j \leq J$, as stated in part (d3) of the Proposition.

Proof of Proposition 6. When $\tilde{n}<N$, any shareholder only needs to offer $U^{o}=\underline{U}$ to attract a manager. When $\tilde{n}=N<n$, the possibility that the best unmatched shareholder, $s_{\tilde{n}+1}$, hires a manager, implies that the minimum utility $U^{o}$ cannot be lower than the level that makes this shareholder not willing to form a firm, i.e., $\widetilde{U}_{\tilde{n}+1, m}$. Finally, the level $U^{o}$ cannot be higher than $\widetilde{U}_{\tilde{n}, m}$ so that $s_{\tilde{n}}$ is still interested in forming a firm. It is then immediate that any contract in a stable outcome should be the best contract for the shareholder when she only needs to offer $U^{o}$ to any manager. Also, given the homogeneity of the managers, all stable outcomes are characterized by a common minimum utility $U^{o}$.

Parts (c1), (c2), and (c3) easily follow given the characteristics of the optimal contract given in Proposition 4 and the fact that $U_{1}^{*}>\ldots>U_{I-1}^{*}>U_{I}^{*}>\ldots>U_{\tilde{n}}^{*}$.

Proof of Propositions 7 and 8. As in the Proof of Proposition 2, let us denote $\theta \equiv \operatorname{Var}+\alpha^{2}$. The proof is by contradiction. Take two matched shareholders $s_{i}$ and $s_{i^{\prime}}$, with $m_{j}=\mu\left(s_{i}\right)$ and $m_{j^{\prime}}=\mu\left(s_{i^{\prime}}\right)$, such that $R_{i}>R_{i^{\prime}}$ while $c_{j}>c_{j^{\prime}}$. Denote by $U_{j}$ and $U_{j^{\prime}}$, the level of utility obtained by managers $m_{j}$ and $m_{j^{\prime}}$ in the stable outcome $(\mu, \mathcal{W})$. It is easy to check that $c_{j}>c_{j^{\prime}}$ implies $U_{j}<U_{j^{\prime}}$. The contracts signed by shareholders $s_{i}$ and $s_{i^{\prime}}$ are, respectively, $W_{s_{i}, m_{j}}\left(U_{j}\right)$ and $W_{s_{i^{\prime}}, m_{j^{\prime}}}\left(U_{j^{\prime}}\right)$.

We are going to prove that unless $W_{s_{i}, m_{j}}\left(U_{j}\right)=W_{s_{i}, m_{j}}^{C B P}\left(U_{j}\right)$ and $W_{s_{i^{\prime}}, m_{j^{\prime}}}\left(U_{j^{\prime}}\right)=$ $W_{s_{i^{\prime}}, m_{j^{\prime}}}^{I S}\left(U_{j^{\prime}}\right)$, the following inequality holds:

$$
\pi_{s_{i}}\left(W_{s_{i}, m_{j^{\prime}}}\left(U_{j^{\prime}}\right)\right)+\pi_{s_{i^{\prime}}}\left(W_{s_{i^{\prime}}, m_{j}}\left(U_{j}\right)\right)>\pi_{s_{i}}\left(W_{s_{i}, m_{j}}\left(U_{j}\right)\right)+\pi_{s_{i^{\prime}}}\left(W_{s_{i^{\prime}}, m_{j^{\prime}}}\left(U_{j^{\prime}}\right)\right) .
$$

Therefore, either $\pi_{s_{i}}\left(W_{s_{i}, m_{j^{\prime}}}\left(U_{j^{\prime}}\right)\right)>\pi_{s_{i}}\left(W_{s_{i}, m_{j}}\left(U_{j}\right)\right)$ or $\pi_{s_{i^{\prime}}}\left(W_{s_{i^{\prime}}, m_{j}}\left(U_{j}\right)\right)>\pi_{s_{i^{\prime}}}\left(W_{s_{i^{\prime}}, m_{j^{\prime}}}\left(U_{j^{\prime}}\right)\right)$. However, this cannot happen in a stable outcome. Indeed, suppose for instance that the first inequality was true. Shareholder $s_{i}$ could offer to $m_{j^{\prime}}$ a contract that would guarantee him an expected utility slightly larger than $U_{j^{\prime}}$ while keeping for herself expected profits larger than $\pi_{s_{i}}\left(W_{s_{i}, m_{j}}\left(U_{j}\right)\right)$. That is, the partnership $\left(s_{i}, m_{j^{\prime}}\right)$ could block the outcome $(\mu, \mathcal{W})$.

We now prove inequality (10).

(a) Consider first that both are IS contracts: $W_{s_{i}, m_{j}}\left(U_{j}\right)=W_{s_{i}, m_{j}}^{I S}\left(U_{j}\right)$ and $W_{s_{i^{\prime}}, m_{j^{\prime}}}\left(U_{j^{\prime}}\right)=$ $W_{s_{i^{\prime}}, m_{j^{\prime}}}^{I S}\left(U_{j^{\prime}}\right)$. From Proposition (2), the optimal payment has a different shape depending 
on the level of utility. We know that $U_{j} \geq \widehat{U}_{i j}$ and $U_{j^{\prime}} \geq \widehat{U}_{i^{\prime} j^{\prime}}$. This also implies that $U_{j} \geq \widehat{U}_{i^{\prime} j}$. We now consider two cases:

(a1) $U_{j^{\prime}} \geq \widehat{U}_{i j^{\prime}}$. In this case, the equation (10) is equivalent to

$$
R_{i} \sqrt{\frac{2 \theta U_{j^{\prime}}}{c_{j^{\prime}}}}-2 U_{j^{\prime}}+R_{i^{\prime}} \sqrt{\frac{2 \theta U_{j}}{c_{j}}}-2 U_{j}>R_{i} \sqrt{\frac{2 \theta U_{j}}{c_{j}}}-2 U_{j}+R_{i^{\prime}} \sqrt{\frac{2 \theta U_{j^{\prime}}}{c_{j^{\prime}}}}-2 U_{j^{\prime}},
$$

which holds given that

$$
\left[R_{i}-R_{i^{\prime}}\right]\left[\sqrt{\frac{U_{j^{\prime}}}{c_{j^{\prime}}}}-\sqrt{\frac{U_{j}}{c_{j}}}\right]>0
$$

(aQ) $U_{j^{\prime}} \in\left[\widehat{U}_{i^{\prime} j^{\prime}}, \widehat{U}_{i j^{\prime}}\right)$. In this case, $\pi_{s_{i}}\left(W_{s_{i}, m_{j^{\prime}}}^{I}\left(\widehat{U}_{i j^{\prime}}\right)\right)=\frac{R_{i}^{2} \theta}{4 c_{j^{\prime}}}$ and (10) is implied by

$$
\frac{R_{i}^{2} \theta}{4 c_{j^{\prime}}}+R_{i^{\prime}} \sqrt{\frac{2 \theta U_{j}}{c_{j}}}-2 U_{j}>R_{i} \sqrt{\frac{2 \theta U_{j}}{c_{j}}}-2 U_{j}+R_{i^{\prime}} \sqrt{\frac{2 \theta U_{j^{\prime}}}{c_{j^{\prime}}}}-2 U_{j^{\prime}}
$$

which is equivalent to

$$
f\left(R_{i}, R_{i^{\prime}}\right)=\frac{R_{i}^{2} \theta}{4 c_{j^{\prime}}}-\left(R_{i^{\prime}} \sqrt{\frac{2 \theta U_{j^{\prime}}}{c_{j^{\prime}}}}-2 U_{j^{\prime}}\right)-\left(R_{i}-R_{i^{\prime}}\right) \sqrt{\frac{2 \theta U_{j}}{c_{j}}}>0 .
$$

We see that $\frac{\partial f\left(R_{i}, R_{i^{\prime}}\right)}{\partial R_{i}}>0$ iff $U_{j}<\widehat{U}_{i j^{\prime}} \frac{c_{j}}{c_{j^{\prime}}}$, which always holds in this region. Then, $f\left(R_{i}, R_{i^{\prime}}\right)>f\left(R_{i^{\prime}}, R_{i^{\prime}}\right)$ for any $R_{i}>R_{i^{\prime}}$, and (10) holds if $g\left(U_{j^{\prime}}\right) \equiv f\left(R_{i^{\prime}}, R_{i^{\prime}}\right)=\frac{R_{i^{\prime}}^{2} \theta}{4 c_{j^{\prime}}}-$ $\left(R_{i^{\prime}} \sqrt{\frac{2 \theta U_{j^{\prime}}}{c_{j^{\prime}}}}-2 U_{j^{\prime}}\right) \geq 0$. It is easy to check that $g\left(U_{j^{\prime}}\right)$ is increasing when $U_{j^{\prime}}>\widehat{U}_{i^{\prime} j^{\prime}}$, having its minimum at $U_{j^{\prime}}=\widehat{U}_{i^{\prime} j^{\prime}}$ where $g\left(\widehat{U}_{i j^{\prime}}\right)=0$. Therefore, (10) holds.

(b) Suppose that all stable contracts include a $C B P$. Equation (10) is implied by:

$$
\frac{R_{i}^{2} \alpha^{2}}{2 c_{j^{\prime}}}-U_{j^{\prime}}+\frac{R_{i^{\prime}}^{2} \alpha^{2}}{2 c_{j}}-U_{j}>\frac{R_{i}^{2} \alpha^{2}}{2 c_{j}}-U_{j}+\frac{R_{i^{\prime}}^{2} \alpha^{2}}{2 c_{j^{\prime}}}-U_{j^{\prime}} \Longleftrightarrow\left[R_{i}^{2}-R_{i^{\prime}}^{2}\right]\left[\frac{1}{c_{j^{\prime}}}-\frac{1}{c_{j}}\right]>0,
$$

which always holds.

(c) We now consider that the existing contracts are $W_{s_{i}, m_{j}}^{I S}\left(U_{j}\right)$ and $W_{s_{i^{\prime}}, m_{j^{\prime}}}^{C B P}\left(U_{j^{\prime}}\right)$. We show that they can not be part of a stable outcome if and only

$$
\pi_{s_{i^{\prime}}}\left(W_{s_{i^{\prime}}, m_{j}}^{I S}\left(U_{j}\right)\right)+\pi_{s_{i}}\left(W_{s_{i}, m_{j^{\prime}}}^{C B P}\left(U_{j^{\prime}}\right)\right)>\pi_{s_{i}}\left(W_{s_{i}, m_{j}}^{I S}\left(U_{j}\right)\right)+\pi_{s_{i^{\prime}}}\left(W_{s_{i^{\prime}}, m_{j^{\prime}}}^{C B P}\left(U_{j^{\prime}}\right)\right)
$$

since either $\left(s_{i^{\prime}}, m_{j}\right)$ or $\left(s_{i}, m_{j^{\prime}}\right)$ can do better than under the original contracts. Given that $U_{j}$ is the level of utility obtained by $m_{j}$, and $\left(s_{i}, m_{j}\right)$ sign an IS contract, it is 
necessarily the case that $U_{j} \geq \widehat{U}_{i j}$. Also, $R_{i}>R_{i^{\prime}}$ implies that $U_{j} \geq \widehat{U}_{i^{\prime} j}$. Therefore, we can rewrite (11) as:

$$
R_{i^{\prime}} \sqrt{\frac{2 \theta U_{j}}{c_{j}}}-2 U_{j}+\frac{R_{i}^{2} \alpha^{2}}{2 c_{j^{\prime}}}-U_{j^{\prime}}>R_{i} \sqrt{\frac{2 \theta U_{j}}{c_{j}}}-2 U_{j}+\frac{R_{i^{\prime}}^{2} \alpha^{2}}{2 c_{j^{\prime}}}-U_{j^{\prime}}
$$

i.e.,

$$
U_{j}<\left[\frac{R_{i}+R_{i^{\prime}}}{2}\right]^{2} \frac{\left[\alpha^{2}\right]^{2}}{2 \theta} \frac{c_{j}}{c_{j^{\prime}}^{2}} .
$$

For the contract $W_{s_{i^{\prime}}, m_{j^{\prime}}}^{C B P}\left(U_{j^{\prime}}\right)$ to be optimal, it is necessarily the case (according to Proposition 4) that $U_{j^{\prime}} \leq U_{i^{\prime} j^{\prime}}^{*}$. Since $U_{j}<U_{j^{\prime}}, U_{j}<U_{i^{\prime} j^{\prime}}^{*}$. Therefore, equation (12) certainly holds if $U_{i^{\prime} j^{\prime}}^{*}$ is lower or equal than the right-hand side of (12). We claim that this is the case. Indeed, when $S r \geq \sqrt{3}$,

$$
\begin{gathered}
U_{i^{\prime} j^{\prime}}^{*}=\frac{R_{i^{\prime}}^{2}}{c_{j^{\prime}}} \frac{\left[\sqrt{\theta}-\sqrt{\theta-\alpha^{2}}\right]^{2}}{2} \leq\left[\frac{R_{i}+R_{i^{\prime}}}{2}\right]^{2} \frac{\left[\alpha^{2}\right]^{2}}{2 \theta} \frac{c_{j}}{c_{j^{\prime}}^{2}} \Longleftrightarrow \\
{\left[\frac{\theta-\sqrt{\theta} \sqrt{\theta-\alpha^{2}}}{\alpha^{2}}\right]^{2} \leq\left[\frac{R_{i}+R_{i^{\prime}}}{2 R_{i^{\prime}}}\right]^{2} \frac{c_{j}}{c_{j^{\prime}}} .}
\end{gathered}
$$

While the right-hand side of the last equation is always larger than 1 , given that $R_{i}>R_{i^{\prime}}$ and $c_{j}>c_{j^{\prime}}$, the left-hand side is smaller or equal than 1 if and only if

$$
\begin{aligned}
\frac{\theta}{\alpha^{2}}-\sqrt{\frac{\theta}{\alpha^{2}} \sqrt{\frac{\theta}{\alpha^{2}}-1}} & \leq 1 \Longleftrightarrow \frac{\theta}{\alpha^{2}}-1 \leq \sqrt{\frac{\theta}{\alpha^{2}}} \sqrt{\frac{\theta}{\alpha^{2}}-1} \Longleftrightarrow \\
\sqrt{\frac{\theta}{\alpha^{2}}-1} & \leq \sqrt{\frac{\theta}{\alpha^{2}}}
\end{aligned}
$$

which always holds. When $\operatorname{Sr} \in(1, \sqrt{3})$, the claim is equivalent to

$$
\frac{R_{i^{\prime}}^{2}}{2 c_{j^{\prime}}}\left[\alpha^{2}-\frac{\theta}{2}\right] \leq\left[\frac{R_{i}+R_{i^{\prime}}}{2}\right]^{2} \frac{\left[\alpha^{2}\right]^{2}}{2 \theta} \frac{c_{j}}{c_{j^{\prime}}^{2}} \Longleftrightarrow \frac{\theta}{\alpha^{2}}-\frac{1}{2}\left[\frac{\theta}{\alpha^{2}}\right]^{2} \leq\left[\frac{R_{i}+R_{i^{\prime}}}{2 R_{i^{\prime}}}\right]^{2} \frac{c_{j}}{c_{j^{\prime}}}
$$

The left-hand side of the equation is always lower than 1. Hence, equation (11) holds and the initial contracts can not be part of a stable outcome.

\section{References}

[1] Adams, R. And D. Ferreira, 2007, "A Theory of Friendly Boards", Journal of Finance 62 (1), 217-250. 
[2] Admati, A.R., P. Pfleiderer and J. Zechner, 1994, "Large Shareholder Activism, Risk Sharing, and Financial Market Equilibrium", Journal of Political Economy 102, 1097-1130.

[3] Agullera, R. and A. Cuervo-Cazurra, 2004, "Codes of Good Governance Worldwide: What is the Trigger?", Organization Studies 25 (3) 415-443.

[4] Alonso-Pauli, E., 2007, "The Adoption of A Code of Best Practice: Incentive Implications", WP Universidad Pablo Olavide de Sevilla.

[5] Arcot, S. And V. Bruno, 2006, "One Size Does Not Fit All, After All: Evidence from Corporate Governance", mimeo.

[6] Barros, F. and I. Macho-Stadler, 1998, "Competition for Managers and Market Efficiency", Journal of Economics and Management Strategy 7, 89-103.

[7] Becht, M., P. Bolton and A. Roell, 2002, "Corporate Governance and Control", Working Paper $N^{o}$ 02/2002 ECGI.

[8] Besley, T. and M. Ghatak, 2005, "Competition and Incentives with motivated agents" The American Economic Review, 95, 617-36

[9] Cadbury Report, 1992, "The report of the Committee on the Financial Aspects of Corporate Governance". London: Gee Publishing.

[10] Crawford, V. and E.M. Knoer, 1981, "Job Matching with Heterogeneous Firms and Workers", Econometrica 49 (2), 437-450.

[11] Dahya, J., J. McConnell and N.V. Travlos, 2002, "The Cadbury Committee, Corporate Performance and Top Management Turnover", Journal of Finance 57, pp. 461-483.

[12] Dam, K. And D. Perez-Castrillo, 2006, "The Principal Agent Market" Frontiers in Economic Theory, Berkeley Electronics, issue 1, article 1.

[13] De Jong, A., D. DeJong, G. Mertens and C. Wasley, 2006, "The Role of Self-Regulation in Corporate Governance: Evidence from The Netherlands", Journal of Corporate Finance 11 (3), 473-503. 
[14] Dow, J. And Raposo, C. 2005, "CEO Compensation, Change, and Corporate Strategy" Journal of Finance, 60 (6) 2701-2727.

[15] Fernandez, E. And S. Gomez, 2002, "Wealth Effects Associated with the Compliance with the Code of Best Practice: The Spanish Experience", mimeo.

[16] Gale, D., 1984, "Equilibrium in a Discrete Exchange Economy with Money", International Journal of Game Theory 13, 41-60.

[17] Gompers, P.A., J. Ishin And A. Metrick, 2003, "Corporate Governance and Equity Prices", Quarterly Journal of Economics 118 (1), 107-155.

[18] Grossman, S. and O. Hart, 1980, "Takeover Bids, the Free-Rider Problem and the Theory of the Corporation", Bell Journal of Economics 11, 42-64.

[19] Hermalin, B. And M. Weisbach, 1998, "Endogenously Chosen Boards of Directors and Their Monitoring of the CEO", The American Economic Review 88, 96-118.

[20] Roman I. and H. Mueller,2005, "Keeping the Board in the Dark: CEO Compensation and Entrenchment" mimeo, New York University, 2005.

[21] IOSCO, 2006, "Board Independence of Listed Companies", consultation Report.

[22] Jensen, M. and W. Meckling, 1976, "Theory of the Firm: Managerial Behavior, Agency Costs and Ownership Structure", Journal of Financial Economics 3, 305-60.

[23] KAneKo,M, 1982, "The central assignment game and the assignment markets" Journal of Mathematical Economics 10, 205-32

[24] La Porta, R., F. Lopez de Silanes And A. Shleifer, 1998, "Law and Finance", Journal of Political Economy 106, 1113-55.

[25] Legros P. And A. Newman, 2002, "Monotone Matching in Perfect and Imperfect Worlds", Review of Economic Studies 69, 925-942

[26] Legros P. And A. Newman, 2007, "Beauty is a Beast, Frog is a Prince: Assortative Matching with Nontransferabilities", Econometrica 75 (4), 1073-102 
[27] Nowak, E., R. Rott and T. Mahr, 2004, "Does Self-regulation Work in a civil Law Country? An Empirical Analysis of the Declaration of Conformity to the German Corporate Governance Code", mimeo.

[28] OECD, 2004, "OECD Principles of Corporate Governance".

[29] Perez-Castrillo, D. and M. Sotomayor, 2002, "A Selling and Buying Procedure", Journal of Economic Theory 103, 461-474.

[30] Prendergast, C., 2002, "The Tenuous Trade-off between Risk and Incentives", The Journal of Political Economy, Vol. 110, 1071-1102

[31] Roth, A. and M. Sotomayor, 1990, "Two-Sided Matching: A Study in GameTheoretic Modeling and Analysis". Cambridge University Press, New York and Melbourne, Econometric Society Monographs.

[32] Serfes, K., 2008, "Endogeneous Matching in a Market with Heterogeneous Principals and agents", International Journal of Game Theory, 36 (3-4), 587-619 .

[33] Shapley, Ll.S. and M. Shubik, 1972, "The Assignment Game I: The Core", International Journal of Game Theory 1, 111-130.

[34] Sharpe, W., 1992, "Asset allocation: Management Style and Performance Measurement", Journal of Portfolio Management, Winter, 7-19

[35] Sotomayor, M., 2002, "A Simultaneous Descending Bid Auction for Multiple Items and Unitary Demand", Revista Brasileira de Economia 56 (3), 497-510. 